\title{
Tests and Analyses of Slotted-In Steel-Plate Connections in Composite Timber Shear Wall Panels
}

\author{
Ulf Arne Girhammar' ${ }^{1}$ and Bo Källsner ${ }^{2}$ \\ ${ }^{1}$ Division of Wood Science and Engineering, Luleå University of Technology, 93187 Skellefteå, Sweden \\ ${ }^{2}$ Department of Building Technology, Linnæus University, 35195 Växjö, Sweden
}

Correspondence should be addressed to Ulf Arne Girhammar; ulf.arne.girhammar@ltu.se

Received 14 July 2016; Accepted 10 October 2016; Published 20 March 2017

Academic Editor: John Mander

Copyright (C) 2017 Ulf Arne Girhammar and Bo Källsner. This is an open access article distributed under the Creative Commons Attribution License, which permits unrestricted use, distribution, and reproduction in any medium, provided the original work is properly cited.

\begin{abstract}
The authors present an experimental and analytical study of slotted-in connections for joining walls in the Masonite flexible building (MFB) system. These connections are used for splicing wall elements and for tying down uplifting forces and resisting horizontal shear forces in stabilizing walls. The connection plates are inserted in a perimeter slot in the PlyBoard ${ }^{\mathrm{TM}}$ panel (a composite laminated wood panel) and fixed mechanically with screw fasteners. The load-bearing capacity of the slotted-in connection is determined experimentally and derived analytically for different failure modes. The test results show ductile postpeak load-slip characteristics, indicating that a plastic design method can be applied to calculate the horizontal load-bearing capacity of this type of shear walls.
\end{abstract}

\section{Introduction}

The introduction of performance based design codes in Sweden 1994 opened for constructing timber buildings higher than two storeys. Since then, the construction of multistorey timber buildings has increased rapidly due to new types of structural components and building systems, reformulation of fire protection regulations, and developments in sound insulation [1]. Nowadays, timber construction technology is highly competitive regarding cost efficiency, sustainability, environmental impact, prefabrication processing, and erection technique.

\section{Masonite Flexible Building System}

The Masonite flexible building (MFB) system is a timber building system developed for industrial manufacturing and construction of multistorey buildings [2]. It encompasses plane units of wall, floor, and roof elements, which all can be customized and prefabricated to a high degree of completion. It is an open building system in the sense that the technical solutions and the erection methods are free to be employed by architects, designers, manufacturers, and construction companies. The system fulfils contemporary requirements regarding fire safety, moisture conditions, strength and stabilization, and thermal and acoustic insulation.

The system is subdivided into two market variants; MFB $\mathrm{XL}$ and MFB Light. The XL system is aimed for large multistorey residential and public buildings up to 8 storeys high and floor spans up to 8 meters while the Light variant is cost optimised for detached houses and smaller buildings with about 3-4 storeys and 4-5 $\mathrm{m}$ floor spans. The main difference between these variants is in the structural design of the floor and the wall elements; whereas XL is a combined panel-frame structural system featuring a special composite laminated wood panel called PlyBoard in combination with I-beams and I-studs, the Light variant utilizes a conventional stud and sheathing construction. Though differing in technical performance, the functional demands are the same. In the following, only the XL system is studied.

2.1. XL Version of Masonite Flexible Building System (MFB $X L$ ). The MFB XL system is a type of combined panel and stud/beam construction for both wall and floor structural elements [3]. The wall elements are mechanically spliced using slotted-in steel connection plates; see Figure 1(a), a front view, and Figure 1(b), a side view. For information, the 

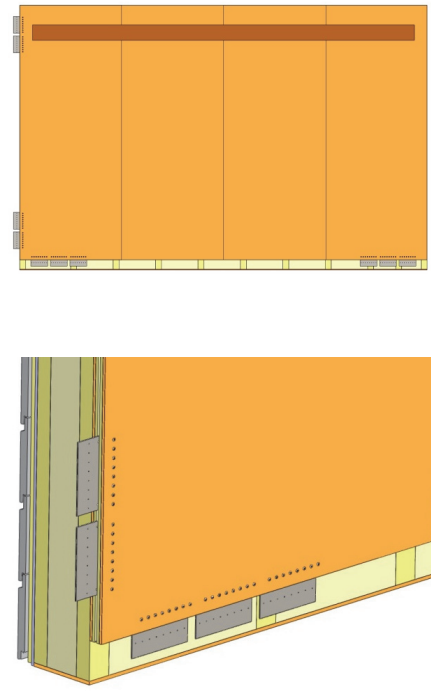

(a)

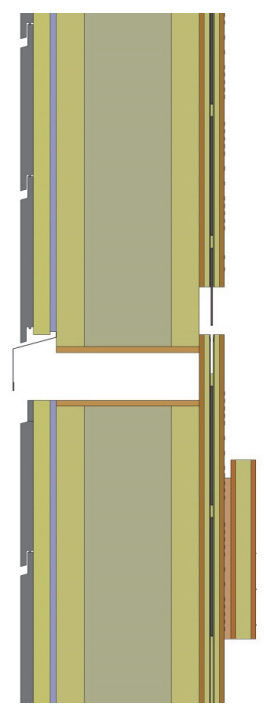

(b)

FIGURE 1: External wall unit of the MFB XL system showing the slotted-in wall-to-wall connections along the bottom and vertical end edge of the wall element: (a) front view (top figure) illustrating a shear wall and left bottom part of the wall (bottom figure). The slotted-in connections are utilized for splicing, anchoring, and load transfer; and (b) an elevated side view showing interface for vertical splicing (the service and finish layers are not shown); the supporting beam on the inner wall surface for the suspended floor elements is also shown.

floor elements are suspended from the walls using sheet steel hanger connections, and the supporting beam on the inner wall surface for the suspended floor elements is also shown in Figure 1.

The structural skeleton of the elements consists of lightweight timber I-beams (for the floors) and I-studs (for the walls) combined with the PlyBoard panel. The structural members are mechanically joined to form a ribbed panel structure. The PlyBoard panel is available in thicknesses between 19 and $42 \mathrm{~mm}$ and the standard format is $1200 \times$ $2400 \mathrm{~mm}$; see Figure 2.

In this paper, the slotted-in steel-plate connection for walls is studied. The associated sheet steel hanger has been analysed in [4].

2.2. Slotted-In Steel-Plate Connection. The MFB system was initially designed with a tie pin connection for the vertical wall-to-wall assembly and as a tie-down device. Due to the high centre tolerance requirements for the pin and the low resistance to withdrawal forces, alternative connection methods were investigated.

The primary objective of a connection is to transfer forces between adjacent members. Its design is of significant importance as it affects the integrity of the whole structure. Principally, there are three basic criteria to consider in the selection of a connection. The strength determines how much force the connection can transfer. This should be accomplished without adverse side effects such as tensile stresses perpendicular to grain. The stiffness of the connection affects the stiffness of the whole structure and thus influences the overall deformation which often is critical in the serviceability limit state. The ductility states the ability to redistribute internal forces within the connection and after maximum load is

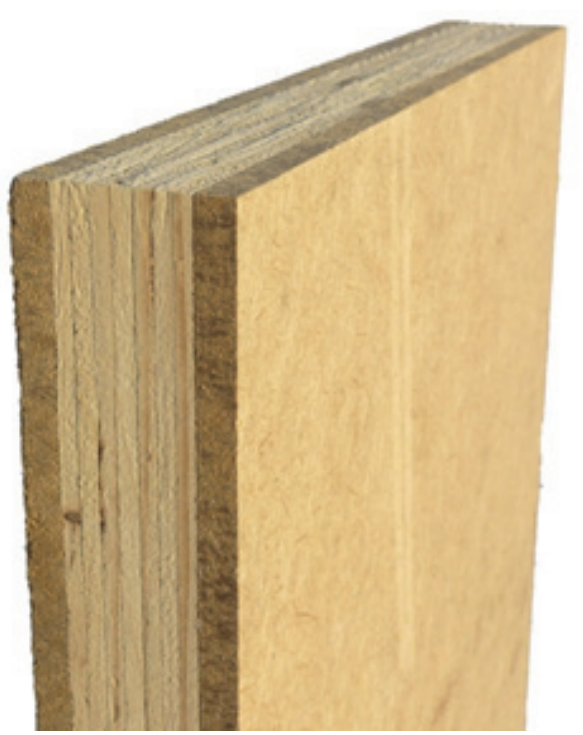

Figure 2: PlyBoard is a three-layered composite wood panel with a core of LVL and surface layers of hard fibreboard [3]. The panel is available in thicknesses between 19 and $42 \mathrm{~mm}$. The standard format is $1200 \times 2400 \mathrm{~mm}$.

reached, to maintain a more or less constant force level under increasing deformations, and hence it governs the region beyond the ultimate load (the postpeak load-displacement characteristics). Connections should exhibit high ductility as this property improves the structural reliability.

Based on these criteria, a connection with slotted-in steel-plate and dowel type fasteners seems to be feasible for the PlyBoard panel in order to achieve a connection with 
high force transfer capacity, ease of installation, configuration flexibility, functional performance, and cost effectiveness.

The slotted-in type of connection is considered as a reliable solution and has been applied in straight and arched long-span glulam trusses for sport arenas, exhibition halls, airports, and timber bridges; see, for example, [5-7].

Figure 1 illustrates the slotted-in steel-plate connection implemented in external wall elements of the MFB system. The steel plate is put in a perimeter slot centred in the PlyBoard panel. This arrangement provides design flexibility such that the number of plates and the screw configuration within the plate can be adapted to prevailing load conditions, and the perimeter slot allows for both vertical and horizontal splicing of wall elements.

\section{Uplift and Shear Test Program}

3.1. Objective. Since the use of slotted-in steel-plate connections in this new kind of PlyBoard panel is a new type of application, an initial experimental study was conducted to investigate the load-displacement relationship, especially the postpeak characteristics to be able to use the new plastic design method for horizontal stability of shear walls; see, for example, [8-15]. The test program included tests to simulate vertical uplift forces induced by wind and horizontal shear forces acting on a shear wall. The test program encompassed test specimens with configurations of one, two, and four screws for the uplift tests and of two and four screws for the shear tests as illustrated in Figure 3.

3.2. Experimental Set-Up. The experiments were conducted using a test rig with a closed-loop servo-hydraulic actuator with a force capacity of $100 \mathrm{kN}$ in both tension and compression. The force was measured by a load-cell mounted on the actuator piston and the displacement of the connection was measured by an optical motion capture system. In both types of test, the specimens were loaded statically under displacement control mode with a rate of the actuator piston between 4 and $6 \mathrm{~mm}$ per minute.

The uplift force was applied by interlinked steel bars with pin connections to avoid restraints in the force transfer and to obtain well-defined boundary conditions; this means that the slotted-in steel plate can rotate slightly, for example, when one of the screws in the connection fails. The shear tests were conducted with a symmetrical specimen configuration, where the force was applied via a rigid C-profile on the top surface of the centre test piece and the side pieces are clamped to the foundation. Since the C-profile was fixed to the vertical bar transferring the applied load, the C-profile could not rotate in case of unsymmetrical failure. (The bar was welded to the steel profile, which caused some restraints and possible uneven application of the load, but on the other hand that design might help straighten up the unbalance that occurs when one part of the specimen fails. However, it would have been better to design that connection as a hinge.) To minimize the friction along the contact areas between the centre and the side pieces, flexible strips of polytetrafluoroethylene (PTFE) foil, a synthetic fluorocarbon solid also known under the brand name of Teflon with a thickness of $0.25 \mathrm{~mm}$ was applied on both contact surfaces (the surfaces were in contact with one another in the beginning of the experiment).

3.3. Optical Displacement Measurement. An optical motion capture system using high-speed infrared video cameras and passive markers attached to test object was used for measuring displacements. The measurement system is developed and marketed by Qualisys AB [16]. In [17] some postprocessing routines necessary to evaluate the test results were developed. The employed system featured three Oqus cameras, lightweight reflex markers, an A/D-board for synchronous data acquisition of motion data from the cameras and analogue voltage data from the load-cell, and a motion capture software (QTM) for data processing and calculation of marker positions. Each camera tracks and records the 2D movement of the individual markers, and by processing the recorded data from several cameras three-dimensional trajectories of the individual markers are obtained. The particular markers used in the tests were plastic half spheres with a diameter of $4 \mathrm{~mm}$. They were attached to the surface of the test object by double sided tape.

In the uplift tests the markers were attached to the top surface of the PlyBoard specimen and to the connection plate just above the joint line. Additional markers were also attached to the surface of the front board, on the head of the screws, and on the foundation plate to get an absolute reference. The joint slip (the relative displacement between the markers on the connection plate and the markers on the PlyBoard top surface) was calculated from the marker trajectories. The accuracy of the displacement measurements was estimated to be better than $0.1 \mathrm{~mm}$.

In the shear tests the markers were attached pairwise, one on each side of the joint, along the two shear planes to measure the movement of the centre test piece relative to the side pieces, that is, the joint slip parallel to the applied force direction. Additional markers were also attached to the head of the screws and on the foundation plate.

3.4. Materials and Specimens. The specimens for both the uplift and the shear tests were made of PlyBoard with dimensions $300 \times 360 \times 42 \mathrm{~mm}(w \times h \times t)($ cf. Figure $4(\mathrm{a}))$. The LVL core was $26 \mathrm{~mm}$ thick with 7 plies; the surface fibreboard layers were $8 \mathrm{~mm}$. The slot width was $4 \mathrm{~mm}$ with a depth of $100 \mathrm{~mm}$. The steel plate was of grade $S 355$ with the dimension $180 \times 160 \times 3 \mathrm{~mm}(w \times h \times t)($ cf. Figure $4(\mathrm{~b}))$.

The uplift tests were carried out parallel to grain and the shear tests perpendicular to grain of the LVL core. In a later stage complementary tests were performed to determine the uplift capacity perpendicular to grain on a single screw connection. These tests used a smaller specimen size, $90 \times$ $280 \times 42 \mathrm{~mm}(w \times h \times t)$, a steel plate of grade S235 with dimension $90 \times 200 \times 3 \mathrm{~mm}(w \times h \times t)$, and ordinary displacement transducers. The PlyBoard panel had been exposed to normal indoor climate for a long time (cf. Table 3).

With respect to erection of the wall elements on site, it was initially thought that it would be rational to use selfdrilling screws to combine drilling and fastening in one 


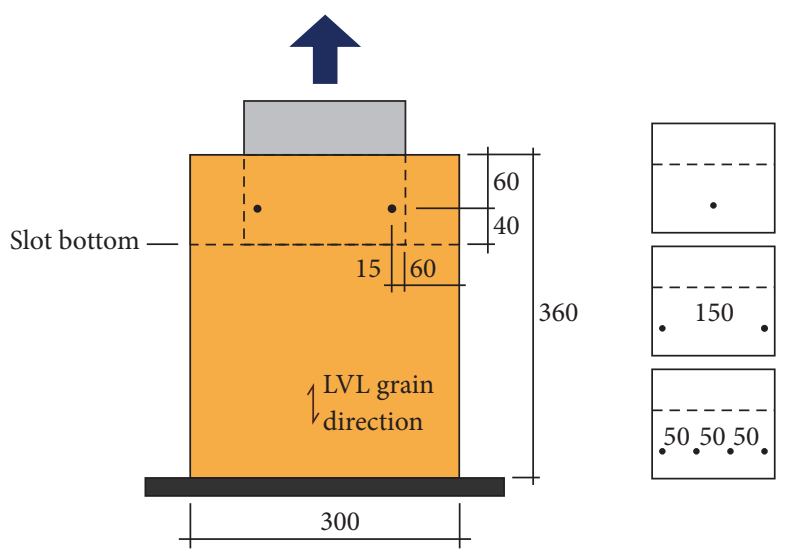

(a)

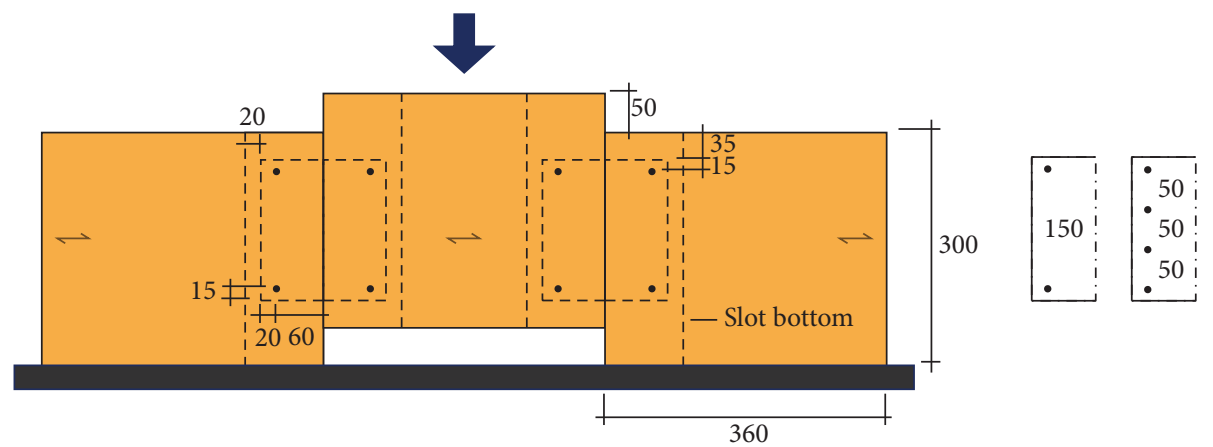

(b)

Figure 3: Test set-up for simulation of (a) vertical uplift force and (b) horizontal shear force (cf. Figure 11). Screw configurations shown to the right, distance to loaded end $60 \mathrm{~mm}$. PlyBoard specimen $300 \times 360 \times 42 \mathrm{~mm}(w \times h \times t)$, steel plate $180 \times 160 \times 3(w \times h \times t)$ for uplift and shear tests of quality S355, and frame screw $6.7 \times 42 \mathrm{~mm}$ (see Figure 4 ).

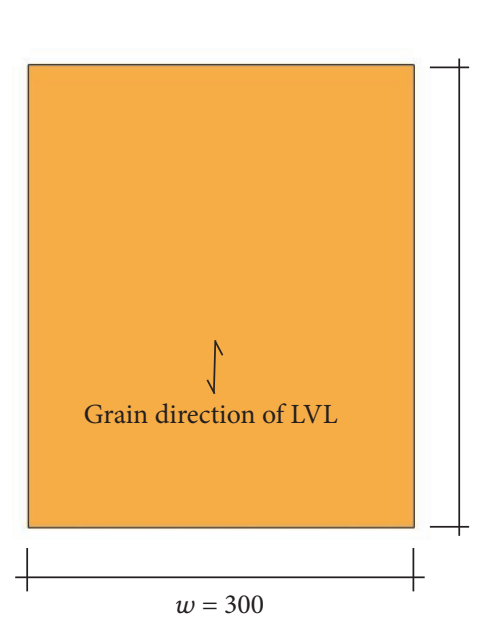

(a)

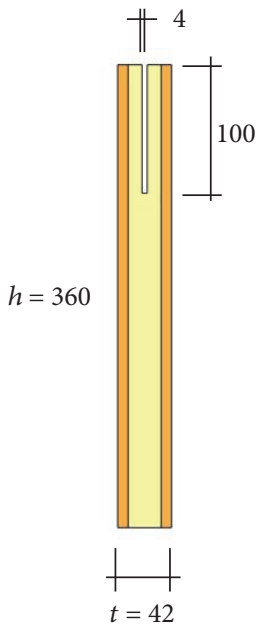

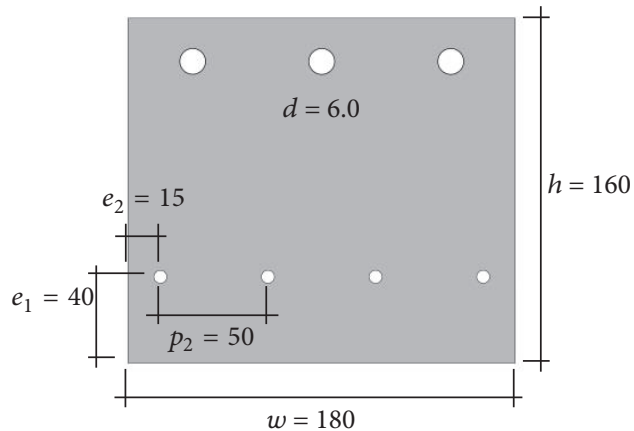

(b)

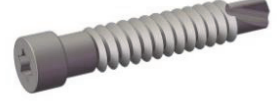

(c)

Figure 4: (a) The PlyBoard specimen, $300 \times 360 \times 42 \mathrm{~mm}$; grain orientation was vertical in the uplift tests and horizontal in the shear tests; (b) the steel connection plate, $180 \times 160 \times 3 \mathrm{~mm}$, quality S355, with hole pattern for the four-fastener configuration; the two-fastener configuration had only the corner holes and the single configuration (used in the uplift tests) had a centre hole; (c) the Adjufix frame screw, self-drilling, size $6.7 \times 42 \mathrm{~mm}, d_{\text {nom }}=6.7 \mathrm{~mm}, d_{\text {eff }}=5.8 \mathrm{~mm}$. Note that the notation in figure (b) corresponds to the notations in (5a), (5b), and (6a) and is valid for the uplift tests. For the shear tests this is changed so that $e_{1}=15 \mathrm{~mm}$ and $e_{2}=40 \mathrm{~mm}$. 
TABLE 1: Result of the uplift tests parallel and perpendicular (single screw only) to LVL grain $(\mathrm{CoV}=$ coefficient of variation; Displ. $=$ displacement).

(a)

\begin{tabular}{|c|c|c|c|c|c|c|c|c|}
\hline \multirow{3}{*}{$\begin{array}{l}\text { Uplift tests } \\
\text { Capacity }\end{array}$} & \multicolumn{4}{|c|}{ Single screw connection } & \multirow{2}{*}{\multicolumn{2}{|c|}{$\begin{array}{c}\text { Double screw connection } \\
\text { Parallel to grain } \\
\text { (4 tests) }\end{array}$}} & \multirow{2}{*}{\multicolumn{2}{|c|}{$\begin{array}{l}\text { Four-screw connection } \\
\text { Parallel to grain } \\
\text { (6 tests) }\end{array}$}} \\
\hline & \multicolumn{2}{|c|}{$\begin{array}{l}\text { Perpendicular to grain } \\
\text { (5 tests) }\end{array}$} & \multicolumn{2}{|c|}{$\begin{array}{c}\text { Parallel to grain } \\
\text { (8 tests) }\end{array}$} & & & & \\
\hline & $\begin{array}{l}\text { Ultimate load } \\
\qquad[\mathrm{kN}]\end{array}$ & $\begin{array}{c}\text { Displ. at } \\
\text { ultimate load } \\
{[\mathrm{mm}]}\end{array}$ & $\begin{array}{l}\text { Ultimate load } \\
\qquad[\mathrm{kN}]\end{array}$ & $\begin{array}{c}\text { Displ. at } \\
\text { ultimate load } \\
{[\mathrm{mm}]}\end{array}$ & $\begin{array}{l}\text { Ultimate load } \\
\qquad[\mathrm{kN}]\end{array}$ & $\begin{array}{c}\text { Displ. at } \\
\text { ultimate load } \\
{[\mathrm{mm}]}\end{array}$ & $\begin{array}{l}\text { Ultimate load } \\
\qquad[\mathrm{kN}]\end{array}$ & $\begin{array}{c}\text { Displ. at } \\
\text { ultimate load } \\
{[\mathrm{mm}]}\end{array}$ \\
\hline $\begin{array}{l}\text { Mean per } \\
\text { connection }\end{array}$ & 5.09 & 2.25 & 7.42 & 2.32 & 13.67 & 3.93 & 25.14 & 3.35 \\
\hline (per screw) & $(5.09)$ & & $(7.42)$ & & $(6.84)$ & & $(6.28)$ & \\
\hline $\mathrm{CoV}[\%]$ & 9.4 & 11 & 9.9 & 8.5 & 18 & 27 & 4.7 & 27 \\
\hline Failure mode & \multicolumn{2}{|c|}{ A } & \multicolumn{2}{|c|}{ B1 } & \multicolumn{2}{|c|}{ B2 } & \multicolumn{2}{|c|}{$\mathrm{B} 2$} \\
\hline
\end{tabular}

A: wood failure in the LVL, initiated by tensile failure followed by shear failure in the LVL-board interface.

B1: brittle type of failure of connection due to brittle bending failure of screw after some plastic deformations; see Figure 8(a).

B2: semiductile type of failure of the connection due to successive (time-lagged) and overlapping mode B1 type of failure of the fasteners.

(b)

\begin{tabular}{lcccc}
\hline \multicolumn{4}{c}{ Stiffness } \\
\hline Mean stiffness & & & & \\
per connection & $7.80 \mathrm{kN} / \mathrm{mm}$ & $12.0 \mathrm{kN} / \mathrm{mm}$ & $19.9 \mathrm{kN} / \mathrm{mm}$ & $48.0 \mathrm{kN} / \mathrm{mm}$ \\
(per screw) & $(7.80 \mathrm{kN} / \mathrm{mm})$ & $(12.0 \mathrm{kN} / \mathrm{mm})$ & $(10.0 \mathrm{kN} / \mathrm{mm})$ & $(12.0 \mathrm{kN} / \mathrm{mm})$ \\
\hline
\end{tabular}

TABLE 2: Result of the shear tests.

(a)

\begin{tabular}{|c|c|c|c|c|}
\hline \multirow{2}{*}{$\begin{array}{l}\text { Shear tests } \\
\text { Capacity }\end{array}$} & \multicolumn{2}{|c|}{$\begin{array}{l}\text { Double screw connection } \\
\text { (8 tests) }\end{array}$} & \multicolumn{2}{|c|}{$\begin{array}{l}\text { Four-screw connection } \\
\text { (8 tests) }\end{array}$} \\
\hline & Ultimate load [kN] & $\begin{array}{l}\text { Displ. at ultimate } \\
\text { load }[\mathrm{mm}]\end{array}$ & Ultimate load [kN] & $\begin{array}{l}\text { Displ. at ultimate } \\
\text { load }[\mathrm{mm}]\end{array}$ \\
\hline Mean per connection & 9.75 & 6.02 & 16.97 & 7.28 \\
\hline (per screw) & $(4.88)$ & & $(4.24)$ & \\
\hline $\mathrm{CoV}[\%]$ & 5.0 & 7.1 & 2.4 & 18.8 \\
\hline Failure mode & \multicolumn{2}{|c|}{$\mathrm{C}$} & \multicolumn{2}{|c|}{$\mathrm{C}$} \\
\hline
\end{tabular}

C: ductile postpeak failure.

(b)

\begin{tabular}{lcc}
\hline & Stiffness & \\
\hline $\begin{array}{l}\text { Mean stiffness per connection } \\
\text { (per screw) }\end{array}$ & $9.60 \mathrm{kN} / \mathrm{mm}$ & $11.3 \mathrm{kN} / \mathrm{mm}$ \\
& $(4.80 \mathrm{kN} / \mathrm{mm})$ & $(2.83 \mathrm{kN} / \mathrm{mm})$ \\
\hline
\end{tabular}

single operation. Different types of self-drilling screws were selected and their drilling capability was evaluated on the PlyBoard specimens with a steel plate inserted in the slot. The drilling was performed with a handheld electric screw driver, but the operation turned out to be very difficult to accomplish since the board surface was hard to penetrate which caused the screws to wobble resulting in enlarged and conical holes. The steel plate was even harder to penetrate and it was only one screw that could be drilled through the steel sheet. The concept of using self-drilling screws was therefore abandoned, instead predrilling and fastening were applied in sequential operations which worked fine. The predrilling was accomplished using a drill of $0.9 d$ (the outer diameter of the screw). Finally, a frame screw with brand name Adjufix, usually used for mounting door and window frames, was selected as shown in Figure 4(c). The dimensions of the frame screw were $6.7 \times 42 \mathrm{~mm}(d \times l)(\mathrm{cf}$. Figure $4(\mathrm{c}))$ and are marketed by Kartro [18].

\section{Test Results and Evaluation}

The results of the uplift and shear tests are summarized in Tables 1 and 2 and described in the following subsections. The results are evaluated focusing on the load-displacement 
TABLE 3: The dry density and the moisture content of the hardboard and LVL materials from the PlyBoard panel. (Eight specimens were used for each kind of test.)

\begin{tabular}{lcccc}
\hline \multirow{2}{*}{ Material } & \multicolumn{2}{c}{ Density $\left[\mathrm{kg} / \mathrm{m}^{3}\right]$} & \multicolumn{2}{c}{ Moisture content [\%] } \\
& Hardboard & LVL & Hardboard & LVL \\
\hline Mean & 950 & 424 & 6.98 & 8.25 \\
CoV [\%] & 1.7 & 5.7 & 1.7 & 1.2 \\
\hline
\end{tabular}

relation with emphasis on the postpeak characteristics since this governs the degree of ductility of the connections.

4.1. Uplift Tests: Loading Parallel to Grain. The displacement is defined as the relative slip between the connection plate and the test specimen, that is, the difference in vertical displacement of the markers on the connection plate just above the joint line and the markers on the top surface of the PlyBoard specimen.

It is important to understand the failure mechanism of a single screw connection as a basis for understanding the behaviour of a multiple screw connection. Hence, special attention is devoted to the failure process of the single screw connection.

4.1.1. Single Screw Connection. Nine tests were conducted in total. One specimen was accidently destroyed during setup and one was deliberately aborted at maximum load for later inspection of the failure mode. The maximum load varied between 6.46 and $8.62 \mathrm{kN}$ with an average of $7.42 \mathrm{kN}$. The corresponding average displacement was $2.3 \mathrm{~mm}$ (cf. Table 1(a)).

The load-displacement curves for the single screw connection are shown in Figure 5(a). The ascending part of the curves is fairly linear up to about $40 \%$ of the maximum load, followed by a gradual decrease in stiffness up to the maximum load. In the postpeak stage, the course of failure followed the same pattern for all tests; a rapid load drop occurred immediately after the maximum load followed by a plateau of variable length where the magnitude of the load remained fairly constant or slightly increased until a second load drop occurred, from there on the load remained more or less constant to the end. The first rapid drop is believed to be due to a crack in the screw normally on one side of the steel plate introducing the brittle failure. However, the other part of the screw is still attached to the steel plate (the screw is screwed into the steel plate) and, therefore, provides some capacity as demonstrated by the plateau. The final stage occurs when the screw separates into two pieces and the residual strength is caused by friction forces arising from the scratching of the broken ends of the screw parts on the surfaces of the steel plate.

Inspection of the broken screw parts after the tests were terminated showed that they were fairly straight, giving support for a localized brittle bending failure at mid-span of the screws. Also, scratch marks could be noticed on the steel plates supporting the explanation that the residual strength is due to friction between the broken screw parts and the steel plate (cf. Figure 6(b)).

Also, the stiffness was evaluated and is shown in Table 1(b). It was evaluated as the secant modulus in the serviceability limit state at $40 \%$ load level of the ultimate load. To get a rough understanding of the degree of resilience for this application compared to ordinary timber connections using dowels, the Eurocode 5 formula $k=\rho_{m}^{1.5} d / 23$ can be used, where $\rho_{m}$ is the geometrical mean value for the density of the PlyBoard. According to values given in Table 3, this stiffness value becomes about $4 \mathrm{kN} / \mathrm{mm}$. Thus, the stiffness of the PlyBoard connection is about 2-3 times higher than predicted by that formula according to the stiffness values given in Table 1.

4.1.2. Double Screw Connection. Six tests were conducted in total; four were executed successfully and two failed due to operational mistakes. The maximum load varied between 11.2 and $16.8 \mathrm{kN}$ with an average of $13.7 \mathrm{kN}$. The corresponding average displacement was $3.9 \mathrm{~mm}$ (cf. Table 1(a)).

As shown in Figure 5(b), the individual curves display a rather large variation. Basically, the characteristic features of the single screw tests can also be recognized here. However, it is noted that the somewhat more complex and irregular curves reflect the superposition of single partial failures in the two screws occurring at different instances.

4.1.3. Four-Screw Connection. Six tests were conducted; all of them were performed successfully. The maximum load varied between 23.7 and $27.1 \mathrm{kN}$ with an average of $25.1 \mathrm{kN}$. The corresponding average displacement was $3.4 \mathrm{~mm}$ (cf. Table 1(a)).

The load-displacement curves are shown in Figure 5(c). The ascending part of the curves is similar to the single screw tests with respect to the first linear part and, then, a gradual decrease in stiffness up to the maximum load. The postpeak part shows a gradual softening with minor load drops, indicating a failure process characterized by sequential failures, overlapping in time, of the screws.

4.1.4. Evaluation Summary. The multiple screw connection curves are characterized by a superposition of the different single screw connection curves. This leads generally to a smoother shape, especially of the postpeak softening part of the load-displacement relationship.

From Table 1 it can be noted that the load-bearing capacity per screw decreases about $8 \%$ for each doubling of the number of screws in the connection. The displacement at ultimate load seems to increase for multiple screw connections compared to single ones.

4.2. Uplift Tests: Loading Perpendicular to Grain. The uplift test perpendicular to the LVL grain was conducted with a different set-up than the parallel tests. This test was confined to a single screw connection and hence a smaller test specimen was used; furthermore the end distance was $35 \mathrm{~mm}$ (7d), the rate of loading was $4 \mathrm{~mm} / \mathrm{min}$ (the same as for the parallel tests), and the optical measurement system was 


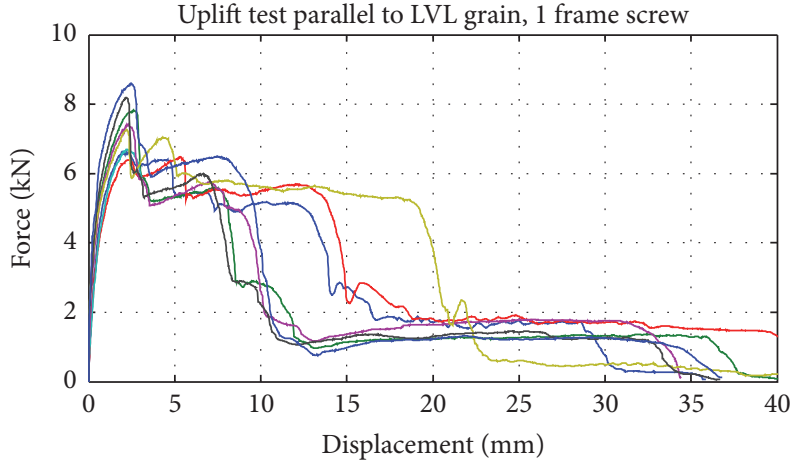

(a)

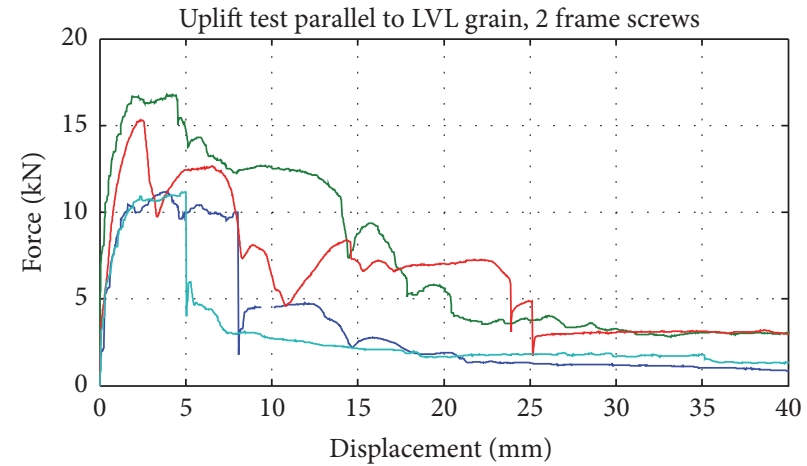

(b)

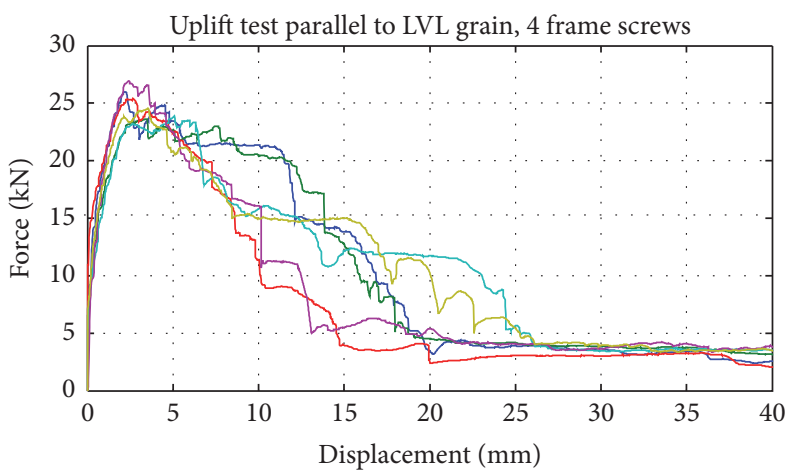

(c)

FIGURE 5: Load-displacement graphs for the uplift tests parallel to the LVL grain with (a) 1 screw, (b) 2 screws, and (c) 4 screws per connection.

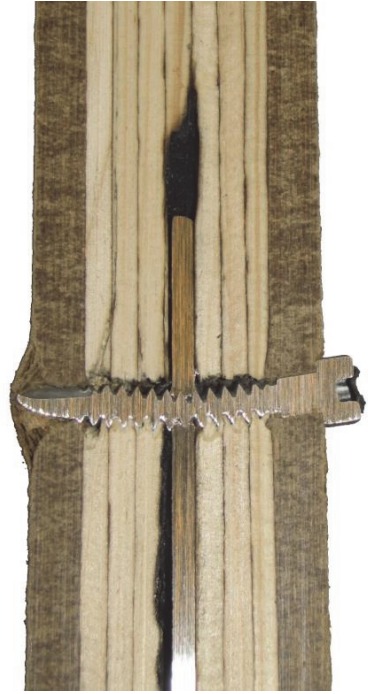

(a)

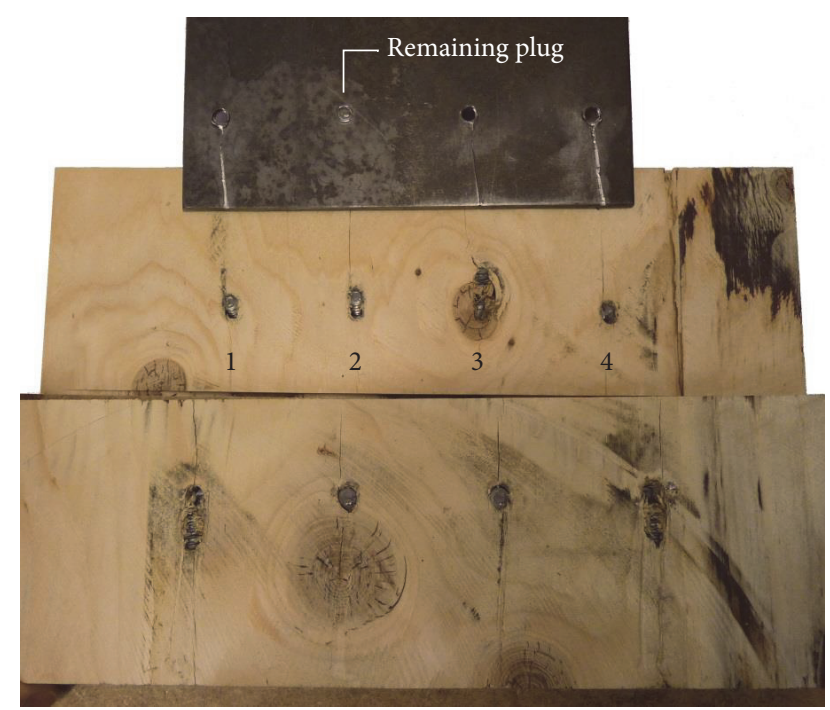

(b)

FIGURE 6: Failure modes for the uplift tests: (a) a cut through the screw of the specimen in the single screw uplift test, which was terminated just after the ultimate load was reached. The screw is slightly bent and is partially broken at the intersection with the steel plate (right side; cf. Figure 10(b)), indicating a brittle type of bending failure; (b) a test of the four-screw configuration after testing showing the inside of the slot where the front part of the PlyBoard has been cut off and folded down and the steel plate has been moved upwards to reveal the interior sides of the slot. It is noted that the screws are heavily indented in the LVL; screws numbers 1 and 4 are also broken at the head-shank interface eventually causing the loose parts to align parallel to the load direction; furthermore hole number 2 holds a remaining plug in the steel plate (the screw has been cut off on both sides) and the plate as well as the LVL shows evident scratch marks especially from screws 1 and 4. 


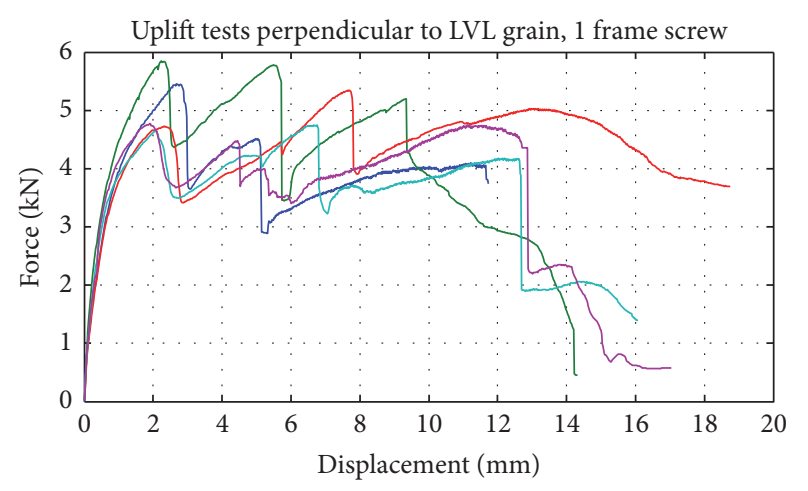

FIgURE 7: Load-displacement curves for uplift tests perpendicular to LVL grain with a single screw connection.

replaced by two ordinary displacement transducers. PlyBoard specimen $90 \times 270 \times 42 \mathrm{~mm}$, steel plate $3 \mathrm{~mm}$ (S235), frame screw $6.7 \times 42 \mathrm{~mm}$, and distance to loaded end $35 \mathrm{~mm}$ were used in the tests.

The results are compiled in Table 1(a) and displayed in Figure 7. The mean ultimate load was $5.09 \mathrm{kN}$ and the corresponding displacement $2.25 \mathrm{~mm}$. Compared with the tests parallel to grain, the ultimate load is 69 percent lower while the corresponding displacement is in the same range.

The loading up to the peak load was often accompanied by audible sounds from cracks in the LVL core (cf. also Section 6.2). Unlike the uplift tests parallel to LVL grain, multiple (usually three) peaks occurred followed by sudden drops of the load, in association with a major crack formation and a loud sound. Thus, the peak region was quite long and characterized by several peaks and drops as shown in Figure 7.

The final failure occurred as a tensile failure in the LVL veneers and a shear failure in the interlayer between the LVL and hardboard sheet at the side of the screw head; see Figure 8. This normally occurred after the third peak. This failure disturbed the displacement readings as the transducers were attached to the top of the specimen.

One test (which had the second highest ultimate load) exhibited at the screw head side a combination of tensile failures in the LVL and hardboard layer and a bending failure in the screw. All other specimens had a screw bending failure followed by a final tensile and shear failure as shown in Figure 8 .

It is obvious that the capacity is much lower in case of loading perpendicular to grain (ca $70 \%$ of the capacity for loading parallel to grain). It means that a cross-ply lay-up should be considered in such cases (Kerto-Q).

4.3. Shear Tests. The shear tests show a rather high degree of ductility, both for the double and for the four-screw configuration; see Figure 9. As expected the individual scatter is less for connections with four screws than those with two.

The average values for the ultimate load and corresponding displacement together with the failure mode are summarized in Table 2. All specimens had ductile postpeak type of failure. The ultimate load-bearing capacity per fastener was $13 \%$ lower for the four-screw connection compared with the double screw connection.

The experiments were conducted with specimens having a gap between the steel plate and the bottom of the slot of $20 \mathrm{~mm}$. Due to the rotation of the steel plates they may come in contact with the LVL at a very large displacement. In reality, the steel plates will be mounted directly to the bottom of the slot. Therefore, the test results underestimate the real shear capacity.

Although measures were taken to reduce the friction in the contact plane between the members by the use of flexible strips of polytetrafluoroethylene (PTFE) foil as mentioned in Section 3.2, it is likely that friction influenced the postpeak ductility. This effect is difficult to estimate as no tests were performed with a gap between the contact surfaces.

The capacities for the shear tests are lower than those for the uplift tests due to the eccentricity of the load transfer and the force direction relative the grain direction; see Section 6.1. The four-screw connection curves are more consistent with less fluctuation compared with the double screw connection curves; this is especially evident beyond the peak load where the load-displacement curves show a smoother and steadier decline. This emanates likely from friction in the contact plane, though it is difficult to estimate how much is due to the higher normal pressure from the rotation of the connection plate and how much is due to the PTFE foil.

4.4. Density and Moisture Content of the PlyBoard. The density and moisture content of the PlyBoard specimens for the parallel tests were evaluated. Eight specimens were used for each kind of test. The specimens were separated into LVL and hardboard pieces of size $60 \times 80 \mathrm{~mm}$ with thickness corresponding to that of the respective layer. The dry density was measured as the oven-dry weight over the oven-dry volume. The results for the density and moisture content are shown in Table 3.

4.5. Strength Value for Screws: Three-Point Bending Tests. The plastic bending moment of the Adjufix frame screw was determined in a three-point bending test. A slotted-in steel plate, $30 \mathrm{~mm}$ wide and $3 \mathrm{~mm}$ thick, was used with a centred oversized hole in which the screw was inserted. As hinged supports two ordinary steel plates were used. Hence, the screw was free to rotate at mid-span and the supports. The span length was equal to $30 \mathrm{~mm}$. Monotonic loading of the steel plate was applied with a displacement rate of approximately $4 \mathrm{~mm} / \mathrm{min}$. The load-displacement curves are shown in Figure 10(a), and a photo of the screw attached to the steel plate is presented in Figure 10(b). The screw shows some plastic bending characteristics, but the final failure is brittle. The average plastic bending moment was determined to $M_{p \text {, mean }}=2827 \times 0.03 / 4=21.2 \mathrm{Nm}($ cf. Figure $10(\mathrm{a}))$.

4.6. Strength Values for PlyBoard: Embedment Tests. In an earlier study [21], the mean embedment strength has been determined experimentally to $f_{h, b}=71.0 \mathrm{~N} / \mathrm{mm}^{2}$ for the hard 


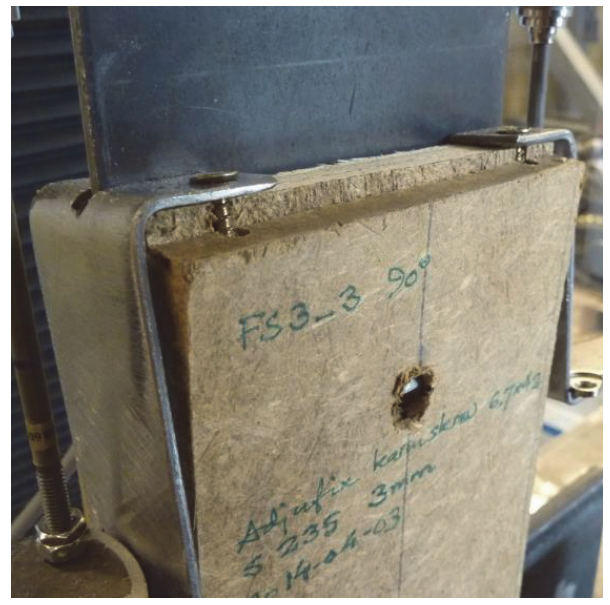

(a)

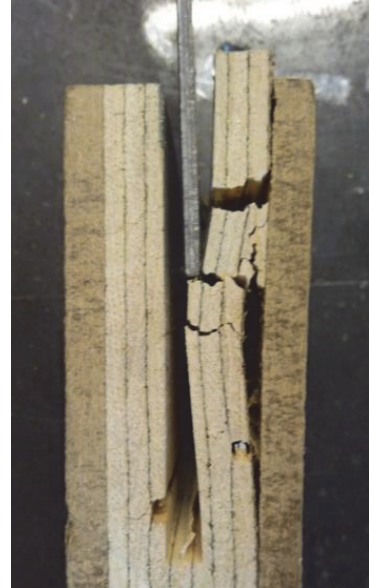

(b)

FIGURE 8: Typical mode of failure for the uplift perpendicular to grain tests, exemplified with specimen number 3: (a) final failure of the LVL at the screw head side (photo taken at a displacement of about $20 \mathrm{~mm}$ ); (b) edge side showing multiple tensile and shear crack formations.

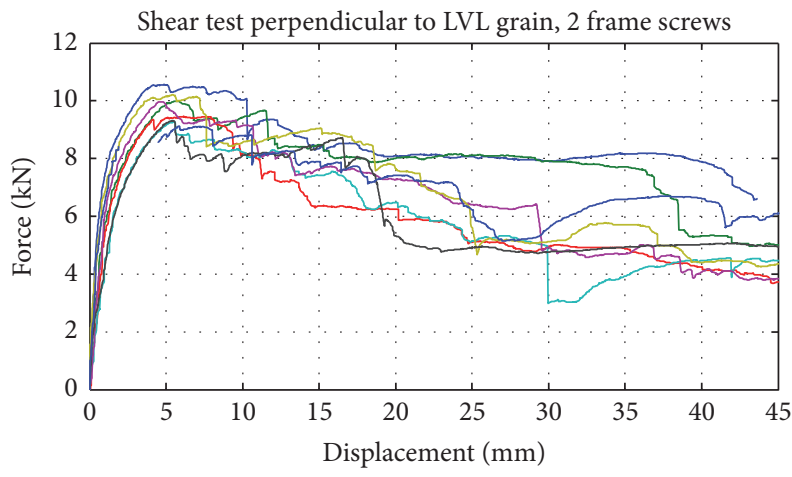

(a)

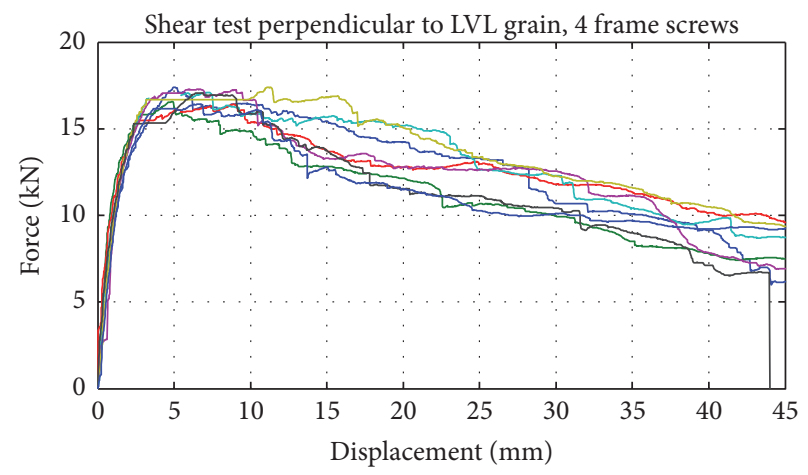

(b)

FIGURE 9: Load-displacement graphs for the shear tests with (a) 2 screws and (b) 4 screws per connection.

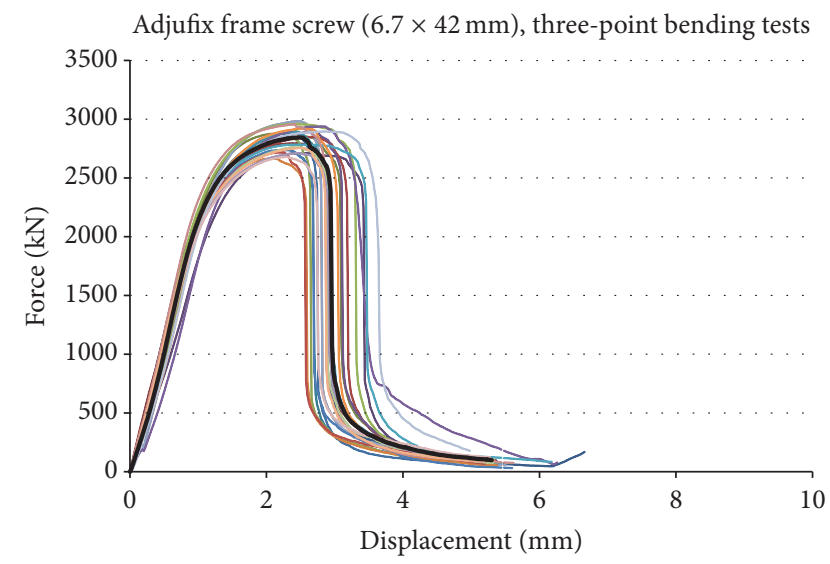

(a)

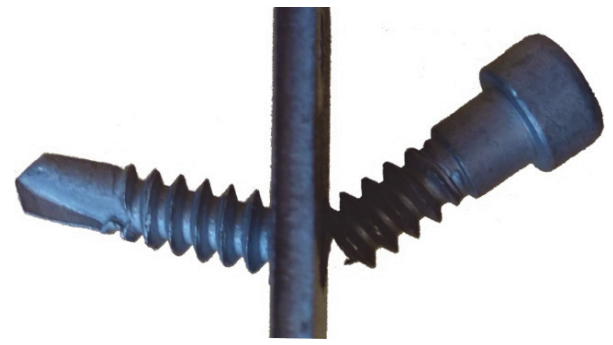

(b)

Figure 10: (a) Load-slip curves from 26 three-point bending tests of the Adjufix frame screw $(6.7 \times 42 \mathrm{~mm})$ (the solid curve is the mean curve) and (b) photo of the screw after failure. 


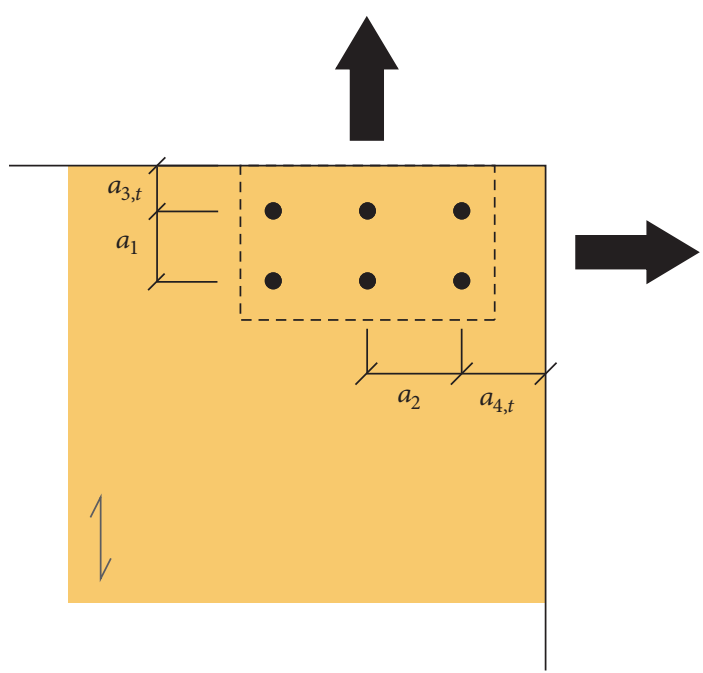

(a)

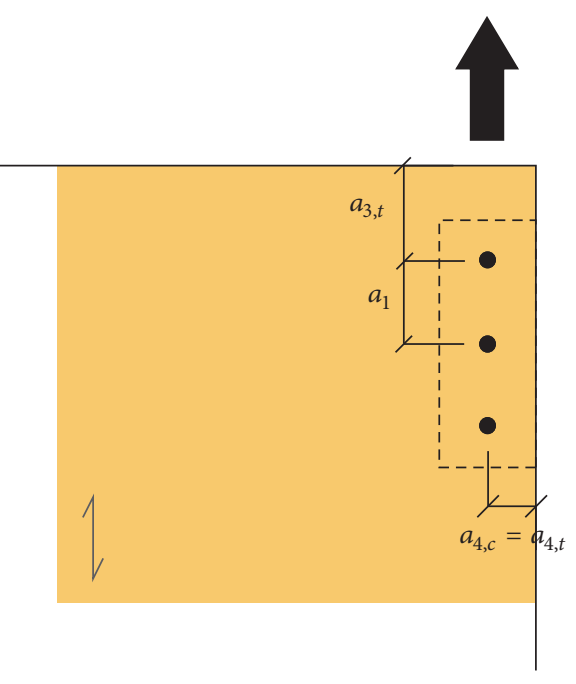

(b)

FIGURE 11: Notations for end and edge distances according to Eurocode 5 [19] for (a) the connection acting as a hold-down (vertical load) and as a shear connection (horizontal load), respectively, and (b) a splice connection between wall elements subjected to a shearing force.

TABLE 4: Recommended minimum values for the end and edge distances shown in Figure 11 with respect to (a) the LVL core as given in [19] for ordinary wood; (b) the hard fibreboard according to [20]; and (c) the PlyBoard panel according to the experimental study presented in Section 4.7. The edge distances for the PlyBoard are estimated because no tests were performed.

\begin{tabular}{|c|c|c|c|c|}
\hline \multirow{2}{*}{$\begin{array}{l}\text { Material in } \\
\text { connection }\end{array}$} & \multicolumn{2}{|c|}{ Hold-down/shear connection } & \multicolumn{2}{|c|}{ Splice connection } \\
\hline & $d \leq 6 \mathrm{~mm}$ & $d>6 \mathrm{~mm}$ & $d \leq 6 \mathrm{~mm}$ & $d>6 \mathrm{~mm}$ \\
\hline LVL & $\begin{array}{c}a_{1}=5 d \\
a_{2}=4 d \\
a_{3, t}=12 d \\
a_{4, t}= \begin{cases}7 d ; & d \geq 5 \mathrm{~mm} \\
5 d ; & d<5 \mathrm{~mm}\end{cases} \end{array}$ & $\begin{array}{c}a_{1}=5 d \\
a_{2}=4 d \\
a_{3, t}=7 d \geq 80 \mathrm{~mm} \\
a_{4, t}=4 d\end{array}$ & $\begin{array}{c}a_{1}=5 d \\
a_{3, t}=12 d \\
a_{4, c}=a_{4, t}=3 d\end{array}$ & $\begin{array}{c}a_{1}=5 d \\
a_{3, t}=7 d \geq 80 \mathrm{~mm} \\
a_{4, c}=a_{4, t}=3 d\end{array}$ \\
\hline $\begin{array}{l}\text { Hard fibreboard } \\
\text { (C40) }\end{array}$ & $\begin{aligned} a_{1} & =4 d \\
a_{4, t} & =4 d\end{aligned}$ & & $\begin{array}{l}a_{3, t}=4 d \\
a_{4, c}=2 d\end{array}$ & \\
\hline PlyBoard & $\begin{array}{l}a_{1}=4 d \\
a_{2}=3 d \\
a_{3, t}=4 d \\
a_{4, t}=5 d\end{array}$ & & $\begin{array}{l}a_{1}=4 d \\
a_{3, t}=4 d \\
a_{4, c}=3 d\end{array}$ & \\
\hline
\end{tabular}

fibreboard layers, $f_{h, w, 0^{\circ}}=49.0 \mathrm{~N} / \mathrm{mm}^{2}$ for the LVL core parallel to grain, and $f_{h, w, 90^{\circ}}=30.0 \mathrm{~N} / \mathrm{mm}^{2}$ for the LVL core perpendicular to grain.

4.7. End and Edge Distances for PlyBoard: Tension Tests. Concerning the edge and end distances in the PlyBoard panel consider Figure 11, where the vertical and horizontal forces act on the slotted-in steel plate. The notations used are those according to Eurocode 5. In Figure 11(a) the slottedin connection serves as a hold-down (vertical uplift force parallel to grain) or as a shear connection (horizontal shear force perpendicular to grain); and in Figure 11(b), the slottedin connection serves as a splice connection between wall panels (vertical shear force parallel to grain). The moment effect from the shear load on the panel is not taken into account. The LVL core is considered as ordinary timber.

In Table 4, the recommended end and edge distances in Figure 11 according to [19] are presented for connections with only LVL and fibreboard, respectively. The longest end or edge distance related to one of the two types of applied forces is used. Holes are assumed to be predrilled and screws with $d \leq 6 \mathrm{~mm}$ (corresponding to nails) and with $d>$ $6 \mathrm{~mm}$ (corresponding to bolts) are considered. For hardboard (C40) alone, the distances are taken from [20] (evaluated for annular ring shanked nails $d=2.1 \mathrm{~mm}$ (to obtain the failure mode plastic bending and withdrawal of the nails); distances $a_{1}$ and $a_{2}$ are not available). In Table 4 , also the evaluated distances for PlyBoard are presented based on the experimental background given below. 
For the PlyBoard a series of tension tests was conducted for different end distances ( $a_{\text {end }}$ varied from $1 d$ to $6 d$ ); the edge distance $\left(a_{\text {edge }}\right)$ was about $8 d$ in all experiments. Steelto-PlyBoard connections in double shear with the thin steel plates as the outer members were used. The screw was a machine screw, that is, corresponding to a bolt, threaded about half of its length. In the PlyBoard panel, a hole was predrilled for the bolt with a diameter equal to that of the bolt. The bolted connection was lightly tightened with a nut (hence, no withdrawal action is at hand). The specimens were loaded both parallel and perpendicular to the grain of the LVL core. Screws of quality 10.9 with a shank diameter of $6 \mathrm{~mm}$ (the outer diameters of the threads were the same) were used. The steel plates were $2 \mathrm{~mm}$ thick and of quality S235. The dimensions of the PlyBoard panel were $93 \mathrm{~mm}$ (width) and $42 \mathrm{~mm}$ (thickness). Three tests were conducted for each configuration. The PlyBoard panel had been exposed to normal indoor climate for a long time (cf. Table 3).

The failure load with respect to yielding of the screw and embedment strength of the PlyBoard and of the steel plate is evaluated in Section 5.2 These values are inserted in Figure 12.

The test results are summarized in Figure 12. In cases where the screw was broken (blue dots), the failure occurred as a brittle failure after some plastic bending of the screw at the intersection between the shank and the threaded part; see Figure 13(b) or Figure 13(e). Screw failure always occurred for $a_{\text {end }} \geq 4 d$ in case of load parallel to grain and $a_{\text {end }} \geq 5 d$ in case of load perpendicular to grain. For cases with load parallel to grain, wood failure (red dots) was initiated when strips above the screw were sheared off in the LVL core together with corresponding local deformations of the hardboard layers (Figure 13(a)). For cases with load perpendicular to grain, tensile failure occurred in the LVL core along the whole width of the PlyBoard specimen together with (i) shear failures at the inner surfaces of the hardboard layers when $a_{\text {end }} \leq 3 d$ (Figure 13(c)) and (ii) corresponding tensile failures of the hardboard layers also along the whole width when $a_{\text {end }} \geq 4 d$ (Figure 13(d)). This failure mode is obviously also depending on the edge distance (in these experiments the edge distance was within $7.8 d-8.4 d$ ).

As mentioned, from Figure 12(a) it is evident that final brittle failure of the screws starts to occur for an end distance of $4 d$ for parallel loading. The lowest value for screw failure is $12.0 \mathrm{kN}$, which exceeds the theoretical failure load $(9.32 \mathrm{kN})$ according to Johansen's yield theory. For loading perpendicular to grain, the corresponding end distance for screw failure is $5 d$ according to Figure 12(b). The edge distance was not tested but kept constant in all tests (about $8 d$ ).

There is a large reinforcing effect by the fibreboard on the LVL core of the PlyBoard panel, especially with respect to the perpendicular to grain direction. The recommended spacings and end and edge distances are shown in Table 4. The spacings $a_{1}$ and $a_{2}$ for PlyBoard are chosen for one unit diameter less than what is applicable for LVL. However, for practical reasons the edge distance $a_{4, c}=a_{4, t}$ in Figure 11(b) for PlyBoard is chosen equal to what is applicable for LVL.

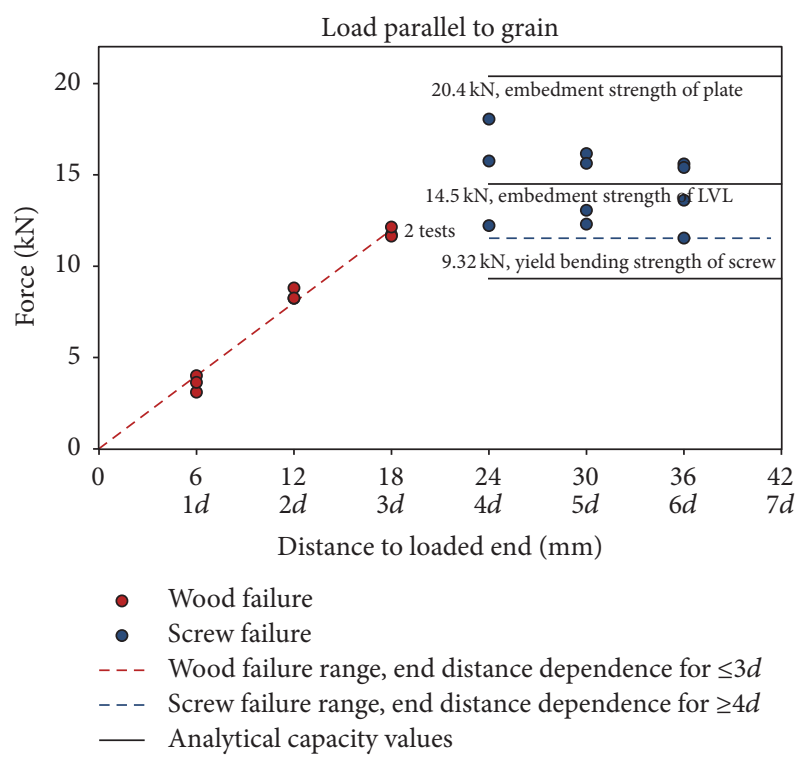

(a)

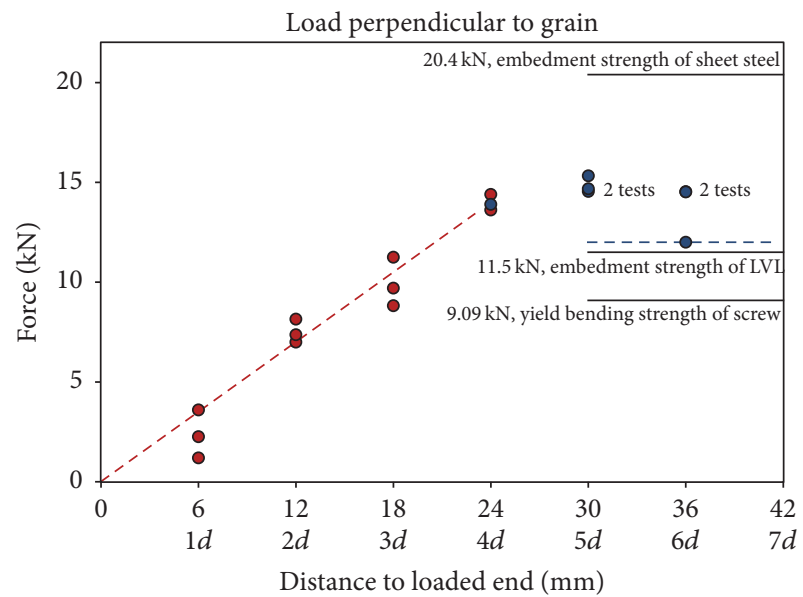

- Wood failure

- Screw failure

- - - Wood failure range, end distance dependence for $\leq 4 d$

- - - Screw failure range, end distance dependence for $\geq 5 d$

— Analytical capacity values

(b)

Figure 12: Results of end distance tests for loading (a) parallel and (b) perpendicular to grain of the LVL core. Three tests were performed for each configuration except for the tests parallel to grain with end distances $5 d$ and $6 d$, where four tests were performed.

\section{Analytical Model for Slotted-In Wall Connection}

5.1. Yield Model for Lateral Load-Carrying Capacity. The capacity of the slotted-in wall connections can be analysed using the European Yield Model (EYM) developed for design of dowel type fasteners, first presented by Johansen [22]. The aim is to apply and extend this plastic model and evaluate the different possible failure modes in the present PlyBoard application, including some special failure modes 


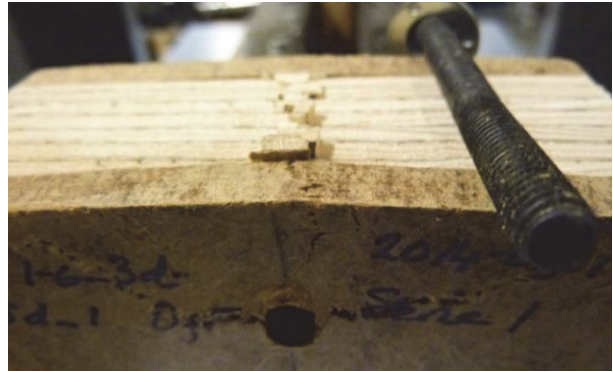

(a)

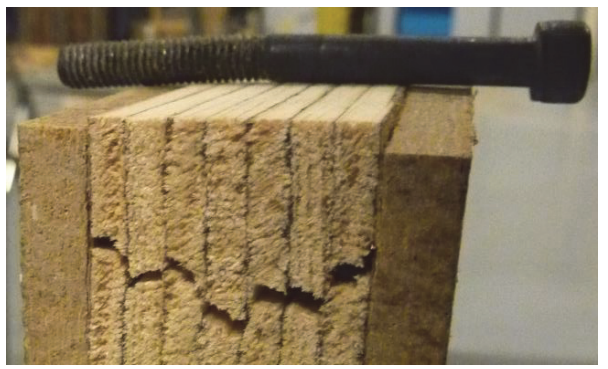

(c)

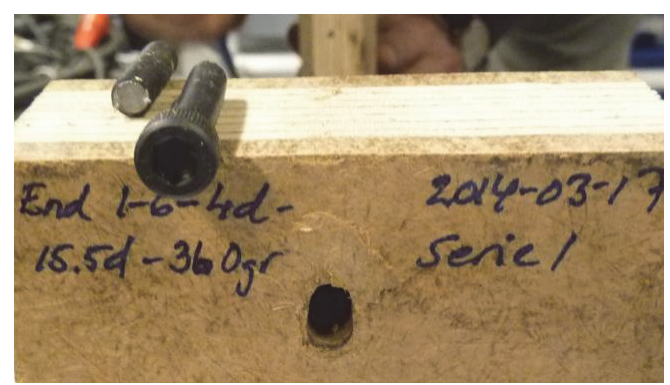

(b)

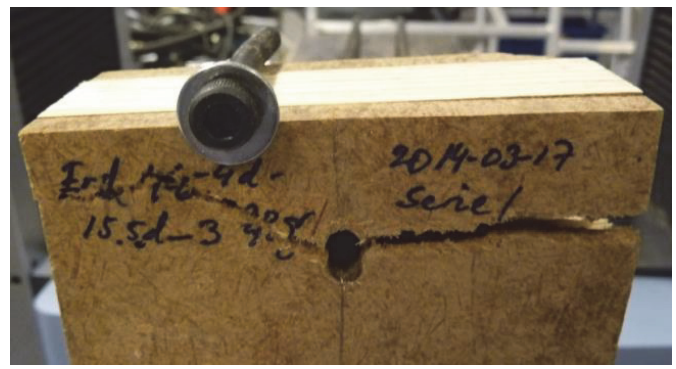

(d)

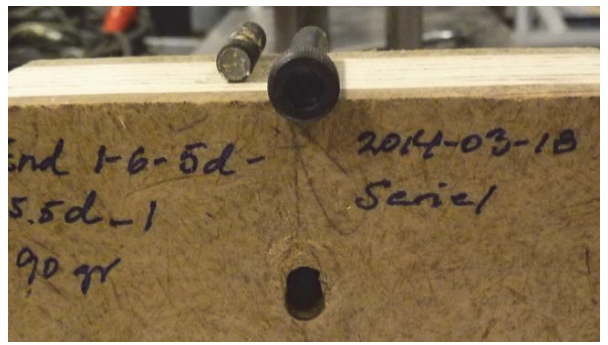

(e)

Figure 13: Typical failure modes for the different configurations for tests parallel (a, b) and perpendicular (c, d, e) to grain: (a) in the wood failure range $a_{\text {end }} \leq 3 d$, the main failure was plug shear failure in the LVL core; (b) in the screw failure range $a_{\text {end }} \geq 4 d$, the screw failed in bending; (c) in the wood failure range $a_{\text {end }} \leq 3 d$, the main failure was in tension in the LVL core and in shear at the hardboard-LVL interface; (d) in the wood failure range $a_{\text {end }} \geq 4 d$, the main failure was in tension both in the LVL core and in the hardboard layers; and (e) in the screw failure range $a_{\text {end }} \geq 5 d$, the screw failed in bending.

characteristic for this case and compare those with the experimental results, and, together with the properties and directions given in Sections 4.5-4.7, to establish a design methodology for the structural engineer to design practical objects and for the manufacturer to be able to optimise the design of the PlyBoard element and its pertaining connection.

In a stabilizing shear wall, the slotted-in connections on the leeward side resist primarily shear forces and the ones on the windward side resist primarily vertical uplift forces. In both cases, the fasteners in the connections are subjected to shear, although with different load to grain directions; at vertical uplift the force is acting parallel to the grain direction of the LVL core, Figure 3(a), and for horizontal shear the force is acting perpendicular to the grain direction, Figure 3(b). This means that, in the analyses below, it is important to consider the angle between the force and the grain direction. The hard fibreboard is assumed to have isotropic properties; that is, they are independent of the force direction.
The following study is limited to the shear capacity of the connections. Failure modes depending on boundary effects such as edge and end distances, as well as tension, shear, and splitting of the PlyBoard panel are not considered. Also, the contribution of the axial force in the fasteners (the rope effect) on the shear capacity of the connections is not included (but can be estimated according to the principles given in Eurocode 5).

The slotted-in steel plate to PlyBoard panel connection can fail in different ways, depending on the strength of the steel and the PlyBoard and on the dimensions of these two components; see Figure 14. Six fundamental failure modes according to Figures 14(a), 14(b), 14(c1), 14(c2), 14(d), and 14(e) are presented and the expressions for their respective load-bearing capacity are given in the following. Also is presented an engineering type of failure mode to evaluate the fact that the embedment strength is much higher in the hardboard layers than in the LVL core (see Figure 14(f)) and a 


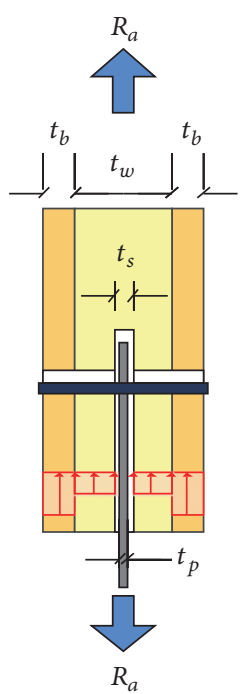

(a) Embedment failure in both LVL and hardboard

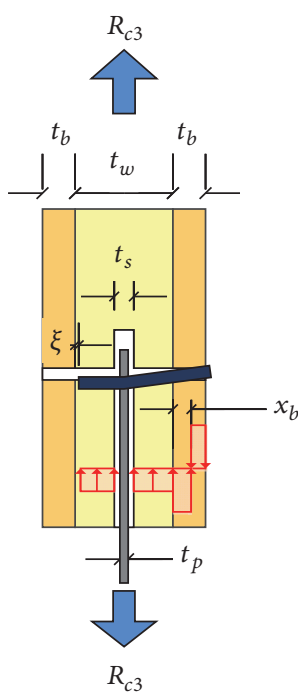

(c3) A special failure mode discussed in Section 6.2. The left hardboard is assumed damaged, one plastic hinge at connection plate

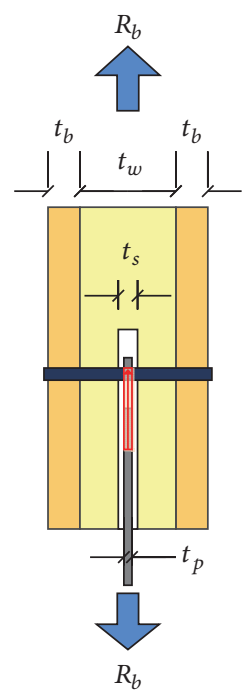

(b) Bearing failure in connection plate

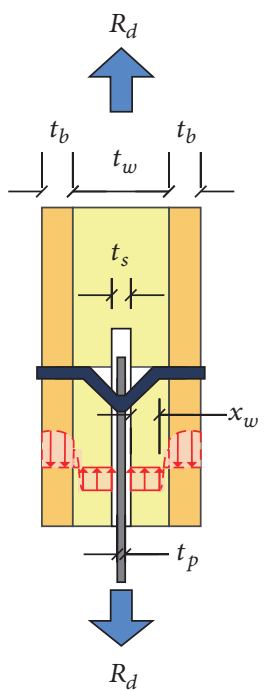

(d) Embedment failure in LVL, two plastic hinges in fastener within LVLcore

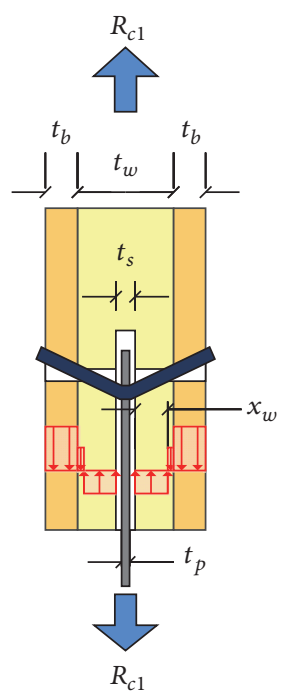

(c1) Embedment failure in both LVL and hardboard with rotation point in LVL, one plastic hinge in fastener

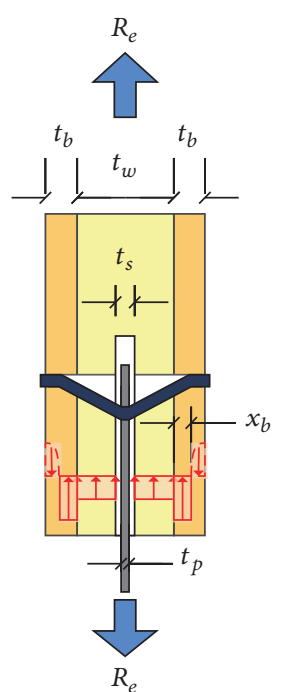

(e) Embedment failure in LVL and partly in hardboard, two plastic hinges in fastener within hardboards

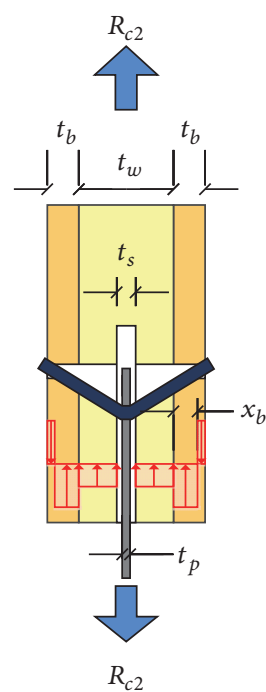

(c2) Embedment failure in LVL and hardboard with rotation point in hardboard, one plastic hinge in the fastener

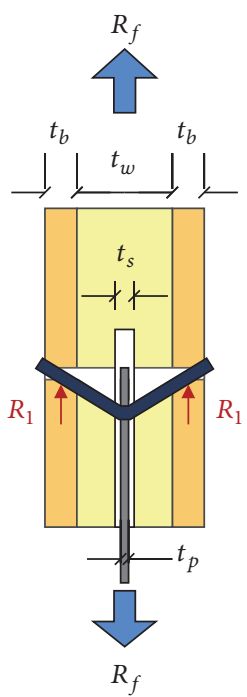

(f) A special failure mode with embedment failure in LVL core; hardboards assumed acting as rigid supports

FIGURE 14: Possible failure modes (a)-(f) for the slotted-in steel plate to PlyBoard panel connection. The force direction corresponds to vertical uplift and is parallel to the grain direction of the LVL core. In the case of horizontal shear the force acts perpendicular to the grain orientation of the LVL core, although the failure mode is principally the same. The influence of edge and end distances is not considered (it is assumed that the edge and end distances proposed in Section 4.7 are applied); the notation and data of the cross-sectional parameters of the PlyBoard test specimens are $t_{b}=$ board thickness $(8 \mathrm{~mm}), t_{w}=$ LVL thickness $(26 \mathrm{~mm}), t_{s}=$ slot thickness $(4 \mathrm{~mm})$, and $t_{p}=$ steel-plate thickness $(3 \mathrm{~mm})$.

special failure mode related to the experiments as discussed in more detail in Section 6.2 (see Figure 14(c3)). It is of interest to evaluate these special cases to know of the sensibility of the failure load and the influence of different parameters and more realistically compare with the experimental results. In the following, only the case with thin metal plates is considered; that is, the thickness of the plate is less than or equal to half the diameter of the fastener $\left(t_{p} \leq 0.5 d\right)$. 
5.1.1. Failure Mode (a): Embedment Failure in Both the LVL Core and the Hardboard Layers. The failure load $R_{a}$ corresponds to embedment failure in the LVL core and the hardboard layers and is derived from vertical equilibrium as

$$
R_{a}=\left[2 f_{h, b} t_{b}+f_{h, w}\left(t_{w}-t_{s}\right)\right] d,
$$

where $f_{h, b}$ and $f_{h, w}$ are the embedment strength of the fibreboard and the LVL core, respectively, $d$ is the diameter of the fastener, and other variables are defined according to Figure 14(a). The width of the slot is $t_{s}=t_{p}+1 \mathrm{~mm}$.

For the case of uplift force the embedment strength parallel to grain of the LVL core, $f_{h, w, 0}$, is used. Similarly, for the shear force, the embedment strength perpendicular to grain of the LVL core, $f_{h, w, 90}$, is applied. With the notation,

$$
\gamma=\frac{f_{h, b}}{f_{h, w}} .
$$

Equation (1) can be written as

$$
R_{a}=f_{h, w} t_{w} d\left[\left(1-\frac{t_{s}}{t_{w}}\right)+2 \gamma \frac{t_{b}}{t_{w}}\right] .
$$

5.1.2. Failure Mode (b): Bearing Failure in the Connection Plate. Bearing failure in the connection plate may occur where the plate is locally yielding. In such a case the failure load $R_{b}$ according to EN 1993-1-8 (cf. Figure 3.1 in this code) is

$$
R_{b}=k_{1} a_{b} f_{u} t_{p} d
$$

where $f_{u}$ is the ultimate strength of the plate; $t_{p}$ is the plate thickness; $d$ is the diameter of the fastener (for wood fasteners the effective diameter, $d_{\text {eff }}$, is used); $k_{1}$ and $a_{b}$ are associated with localized fracture.

The coefficient $k_{1}$ accounts for tension fracture perpendicular to the direction of load transfer, including the effect of the edge distance $e_{2}$ and the centre distance between adjacent lines of fasteners $p_{2}$ as presented in (5a) and (5b), respectively,

$$
\begin{array}{ll}
k_{1}=2.8 \frac{e_{2}}{d_{0}}-1.7 \leq 2.5 \text { for edge screws } \\
k_{1}=1.4 \frac{p_{2}}{d_{0}}-1.7 \leq 2.5 \text { for interior screws, }
\end{array}
$$

where $d_{0}$ is the hole diameter $\left(d_{0}=0.9 d_{\text {nom }}=0.9 \cdot 6.7=\right.$ $6.0 \mathrm{~mm})$. In case of no influence of the edge and centre distances (i.e., $k_{1}=2.5$ ), the edge distance should be $e_{2} \geq$ $1.5 d_{0}$ and the centre distance $p_{2} \geq 3 d_{0}$. The coefficient $a_{b}$ is the smallest value of these three conditions,

$$
a_{b}=\min \left\{\begin{array}{c}
\alpha_{d} \\
\frac{f_{u b}}{f_{u}} \\
1.0
\end{array}\right.
$$

where $f_{u b} / f_{u}$ is the ratio between the ultimate strengths of the bolt and of the plate material, respectively, and the coefficient $\alpha_{d}$ is associated with plate tear-out by shearing in the direction of load transfer, associated with the end distance $\left(e_{1}\right)$ or the spacing between the rows of fasteners $\left(p_{1}\right)$ as given in (6a) and (6b), respectively,

$$
\begin{aligned}
& \alpha_{d}=\frac{e_{1}}{3 d_{0}} \leq 1 \quad \text { for end screws } \\
& \alpha_{d}=\frac{p_{1}}{3 d_{0}}-0.25 \leq 1 \quad \text { for interior screws. }
\end{aligned}
$$

For end distances $e_{1} \geq 3 d_{0}$ and centre distances $p_{2} \geq 3.75 d_{0}$, the coefficient $\alpha_{d}=1$; that is, there is no influence of end or centre distances.

The geometrical data for the connection plate (Figure 4 ) give $k_{1}=2.5\left(e_{2}=15 \mathrm{~mm} ; d_{0}=6.0 \mathrm{~mm}\right)$ and $a_{b}=1.0\left(e_{1}=\right.$ $\left.40 \mathrm{~mm} ; f_{u b}=650 \mathrm{MPa} ; f_{u}=490 \mathrm{MPa}\right)$ in all cases except for shearing with four screws, where $a_{b}=\alpha_{d}=0.833$ with $e_{1}=$ $15 \mathrm{~mm}$ ( $=e_{2}$ in Figure 4 as noted in the capture of the figure).

5.1.3. Failure Mode (c1): Embedment Failure in Both the LVL Core and the Hardboard Layers Combined with a Plastic Hinge in the Fastener; Sign Shift of the Shear Force within the LVL Core. The failure load $R_{c 1}$ corresponds to embedment failure in both the LVL core and the hardboard layers combined with a plastic hinge in the fastener at the connection plate. This failure mode is likely not realistic. It is derived from vertical equilibrium to give

$$
R_{c 1}=2 f_{h, w} t_{w} d\left[2 \frac{x_{w}}{t_{w}}-\frac{1}{2}\left(1-\frac{t_{s}}{t_{w}}\right)-\gamma \frac{t_{b}}{t_{w}}\right],
$$

where the distance $x_{w}$ is determined from moment equilibrium at the centre of the cross-section; that is,

$$
\begin{aligned}
& M_{p} \\
& =\frac{1}{2} f_{h, w} d\left[2 x_{w}^{2}+2 t_{s} x_{w}-\frac{1}{4}\left(t_{w}^{2}-t_{s}^{2}\right)-\gamma t_{b}\left(t_{w}+t_{b}\right)\right]
\end{aligned}
$$

or

$$
\begin{aligned}
& x_{w}=\frac{1}{2} t_{s}[-1 \\
& +\sqrt{\left.1+\frac{4 M_{p}}{f_{h, w} t_{s}^{2} d}+\frac{1}{2}\left(\frac{t_{w}^{2}}{t_{s}^{2}}-1\right)+2 \gamma \frac{t_{b}}{t_{s}}\left(\frac{t_{w}}{t_{s}}+\frac{t_{b}}{t_{s}}\right)\right]} \\
& \quad 0 \leq x_{w}<\frac{1}{2}\left(t_{w}-t_{s}\right) .
\end{aligned}
$$

5.1.4. Failure Mode (c2): Embedment Failure in Both the LVL Core and the Hardboard Layers Combined with a Plastic Hinge in the Fastener; Sign Shift of the Shear Force within the Board Layers. This failure mode is similar to the previous mode with the exception that the sign shift of the shear force takes place within the board layers. The load-carrying capacity is

$$
R_{c 2}=2 f_{h, w} t_{w} d\left[\gamma \frac{t_{b}}{t_{w}}\left(2 \frac{x_{b}}{t_{b}}-1\right)+\frac{1}{2}\left(1-\frac{t_{s}}{t_{w}}\right)\right],
$$


where, from moment equilibrium,

$$
\begin{aligned}
M_{p} & =\frac{1}{2} f_{h, w} d\left[\gamma\left(2 x_{b}^{2}+2 t_{w} x_{b}-t_{b}\left(t_{b}+t_{w}\right)\right)\right. \\
& \left.+\frac{1}{4}\left(t_{w}^{2}-t_{s}^{2}\right)\right]
\end{aligned}
$$

and the distance $x_{b}$ is given by

$$
\begin{aligned}
& x_{b}=\frac{1}{2} t_{w}[-1 \\
&+\left.\sqrt{1+\frac{4 M_{p}}{\gamma f_{h, w} t_{w}^{2} d}-\frac{1}{2 \gamma}\left(1-\frac{t_{s}^{2}}{t_{w}^{2}}\right)+2 \frac{t_{b}}{t_{w}}\left(1+\frac{t_{b}}{t_{w}}\right)}\right] ; \\
& 0 \leq x_{b}<t_{b} .
\end{aligned}
$$

5.1.5. Failure Mode (d): Embedment Failure in the LVL Core and Three Plastic Hinges in the Fastener. The failure load $R_{d}$ corresponds to embedment failure in the central part of the LVL core and double plastic hinges in the fastener within the LVL. The load-bearing capacity is given by

$$
R_{d}=2 f_{h, w} x_{w} d
$$

where from moment equilibrium

$$
2 M_{p}=\frac{1}{2} f_{h, w} d\left(x_{w}^{2}+t_{s} x_{w}\right)
$$

and $x_{w}$ is given by

$$
\begin{aligned}
x_{w}=\frac{1}{2} t_{s}\left[-1+\sqrt{\left.1+\frac{16 M_{p}}{f_{h, w} d t_{s}^{2}}\right]}\right. & \\
& 0 \leq x_{w}<\frac{1}{2}\left(t_{w}-t_{s}\right) .
\end{aligned}
$$

5.1.6. Failure Mode (e): Embedment Failure in the Whole LVL Core and Part of the Hardboard Layers plus Three Plastic Hinges in the Fastener. The failure load $R_{e}$ corresponds to embedment failure in the whole LVL core and parts of the hardboard layers in combination with three plastic hinges, one within the LVL core and two in the hardboard layers. The capacity is given by

$$
R_{e}=f_{h, w} t_{w} d\left(1-\frac{t_{s}}{t_{w}}+2 \gamma \frac{x_{b}}{t_{w}}\right),
$$

where from moment equilibrium

$$
\begin{aligned}
2 M_{p}=f_{h, w} d\left[\frac{1}{8}\left(t_{w}^{2}-t_{s}^{2}\right)+\frac{1}{2} \gamma\left(x_{b}^{2}+x_{b} t_{w}\right)\right] & \\
0 & \leq x_{b}<t_{b} .
\end{aligned}
$$

And the distance $x_{b}$ is given by

$$
\begin{array}{r}
x_{b}=\frac{1}{2} t_{w}\left[-1+\sqrt{1+\frac{16 M_{p}}{f_{h, b} d t_{w}^{2}}-\frac{1}{\gamma}\left(1-\frac{t_{s}^{2}}{t_{w}^{2}}\right)}\right] \\
0 \leq x_{b}<t_{b} .
\end{array}
$$

The clamping effect of the screw head against the hardboard layer is not considered.

\subsubsection{Failure Mode (f): Embedment Failure in the LVL Core and} the Hardboard Layers Are Assumed to Act as Rigid Supports. Here an engineering type of failure mode is added for reasons of comparison and to evaluate the dominating behaviour. It is noted that the embedment strength is about $50 \%$ (parallel to grain) and $130 \%$ (perpendicular to grain) higher, respectively, in the outer hardboard layers than in the LVL core and, hence, the board layers tend to act as rigid supports for the fastener relative to the rather soft core. Consequently, in the model the failure load $R_{f}$ corresponds to embedment failure in the LVL core while the hardboard layers act as rigid supports. The ideal situation is here assumed where the fastener extends beyond the rear hardboard layer.

If the fastener is assumed to rotate around the centre of the board layer, the vertical equilibrium gives

$$
R_{f}=2 R_{1}+f_{h, w} d\left(t_{w}-t_{s}\right)+f_{h, b} d \frac{1}{2} t_{b}-f_{h, b} d \frac{1}{2} t_{b}
$$

Moment equilibrium at the centre of the cross-section gives

$$
\begin{aligned}
R_{1} \frac{t_{w}+t_{b}}{2}= & M_{p}-f_{h, w} d\left(\frac{t_{w}-t_{s}}{2}\right)\left(\frac{t_{w}-t_{s}}{4}+\frac{t_{s}}{2}\right) \\
& -f_{h, b} d \frac{1}{2} t_{b}\left(\frac{t_{w}}{2}+\frac{t_{b}}{4}\right) \\
& +f_{h, b} d \frac{1}{2} t_{b}\left(\frac{t_{w}}{2}+\frac{3 t_{b}}{4}\right)
\end{aligned}
$$

which leads to

$$
R_{1}=\frac{2 M_{p}}{t_{w}+t_{b}}-f_{h, w} d \frac{t_{w}^{2}-t_{s}^{2}}{4\left(t_{w}+t_{b}\right)}+f_{h, b} d \frac{t_{b}^{2}}{2\left(t_{w}+t_{b}\right)} .
$$

Equation (19) becomes

$$
\begin{aligned}
R_{f} & =f_{h, w} d\left(t_{w}-t_{s}\right)\left[1-\frac{1}{2} \frac{t_{w}+t_{s}}{t_{w}+t_{b}}\right. \\
& \left.+\frac{4 M_{p}}{f_{h, w} d\left(t_{w}-t_{s}\right)\left(t_{w}+t_{b}\right)}+\frac{\gamma t_{b}^{2}}{\left(t_{w}-t_{s}\right)\left(t_{w}+t_{b}\right)}\right] .
\end{aligned}
$$

Equation (22) overestimates the load-bearing capacity due to some support displacement in the board layers but underestimates it on the other hand somewhat due to the clamping effect of the screw head against the hardboard layer.

For all the failure modes $(a)-(f)$, the proper embedment strength should be used; that is, $f_{h, w}=f_{h, w, 0}$ for force parallel to grain (e.g., the uplift force) and $f_{h, w}=f_{h, w, 90}$ for force perpendicular to grain, respectively. (For an arbitrary angle $\beta, f_{h, w}=f_{h, w, \beta}$ should be used as discussed in Section 6.1 for eccentrically applied (shear) forces.) Also, in all failure modes, the contribution from the axial force in the fastener is not included. 


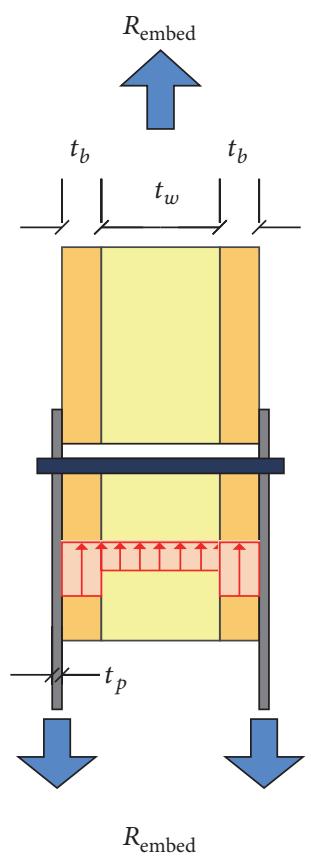

(a)

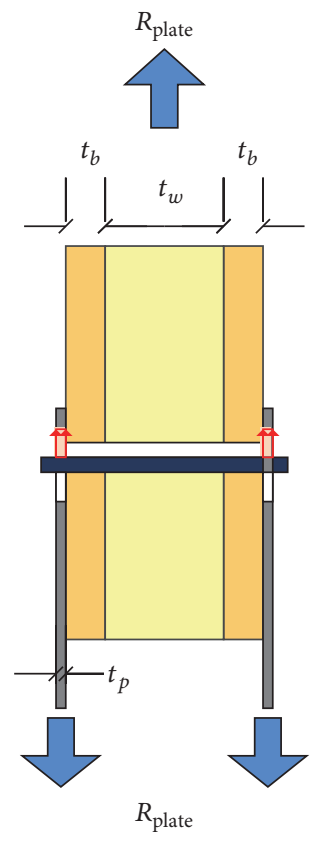

(b)

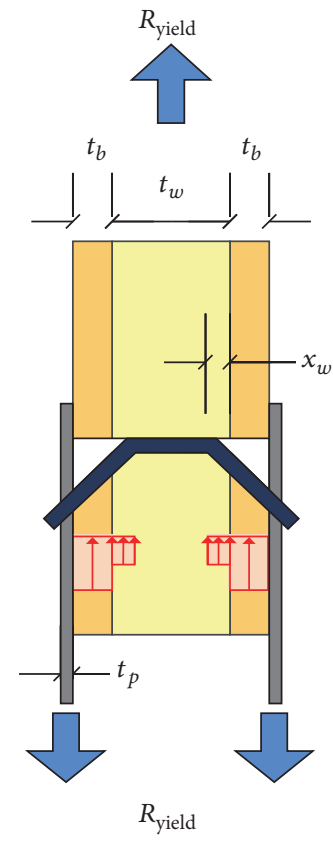

(c)

Figure 15: Possible failure modes (a)-(c) for double exterior connection plates corresponding to the tests discussed in Section 4.7: (a) embedment failure in the PlyBoard panel; (b) embedment failure in the steel plates; and (c) yielding of screw.

5.2. Evaluation of Load-Carrying Capacity of Tests on End and Edge Distances for PlyBoard. Consider the three possible failure modes in Figure 15 for the test set-up for determining the end and edge distances for PlyBoard.

The failure load with respect to embedment strength of the panel $\left(R_{\text {embed }}\right.$, Figure 15(a)) is given by (1) with $t_{s}=0$ and concerning the embedment strength of the steel plate $\left(R_{\text {plate }}\right.$, Figure 15(b)) by (4) multiplied by 2 .

For the failure mode yielding of the screw $\left(R_{\text {yield }}\right.$, Figure 15(c)), the failure load corresponds to embedment failure in the hardboard and partially in the LVL core and screw failure with double plastic hinges within the LVL. Vertical equilibrium for the whole connection and moment equilibrium at the location of the steel plate for the right part beyond the location of the plastic hinge in the screw give

$$
\begin{aligned}
R_{\text {yield }} & =2\left(f_{h, w} x_{w}+f_{h, b} t_{b}\right) d, \\
M_{p} & =f_{h, w} d x_{w}\left(\frac{1}{2} x_{w}+t_{b}\right)+\frac{1}{2} f_{h, b} d t_{b}^{2} .
\end{aligned}
$$

From the latter equation, the location $x_{w}\left(0 \leq x_{w}<t_{w} / 2\right)$ can be evaluated. Then, the load-carrying capacity is given by

$$
R_{\text {yield }}=2 f_{h, w} d t_{b}\left[\sqrt{1-\gamma+\frac{2 M_{p}}{f_{h, w} d t_{b}^{2}}}+\frac{\gamma-1}{f_{h, w} d t_{b}}\right]
$$

With parameters according to those mentioned in Sections 3 and 4 and those in Section 6.2, the failure loads for loading parallel to grain become for the screw, $R_{\text {yield }}=9.32 \mathrm{kN}$
$\left(M_{p}=f_{y} d_{\mathrm{eff}}^{3} / 6=900 \cdot 0.0056^{3} / 6=26.3 \mathrm{Nm}\right)$, for the PlyBoard panel, $R_{\text {embed }}=14.5 \mathrm{kN}$, and the corresponding failure loads for loading perpendicular to grain, $R_{\text {yield }}=9.09 \mathrm{kN}$ and $R_{\text {embed }}=11.5 \mathrm{kN}$. The failure load with respect to the embedment strength of the steel plate is $R_{\text {plate }}=20.4 \mathrm{kN}$. These values are inserted in Figure 12.

\section{Load-Bearing Capacity}

6.1. Lateral Load-Bearing Capacity of Fasteners. The experiments presented and described in Sections 3 and 4 are compared with the derived analytical capacities of Section 5. For the uplift tests, the forces in the individual fasteners are readily given by the applied load. For the shear tests, however, the eccentricity in the load transfer between the mid and side pieces of the specimen needs to be accounted for.

To study the effect of eccentricity on the fastener forces, consider the shear tests in Figure 3(b). The configuration for two and four screws is displayed in Figure 16. The eccentricity between the transferred shear force and the location of the fasteners gives rise to a moment introducing additional forces in the fasteners. Assume that all screws are completely plasticized.

Here a simple assumption is made concerning the statics of the load transfer between the mid and side pieces of the specimen. For the two-screw configuration, the fastener reaction force due to the applied shear force $F_{v}$ is determined from vertical equilibrium, and the fastener reaction force due to the eccentricity moment $F_{v} e$ is determined from moment equilibrium at the centre of gravity (CG) of the screw 


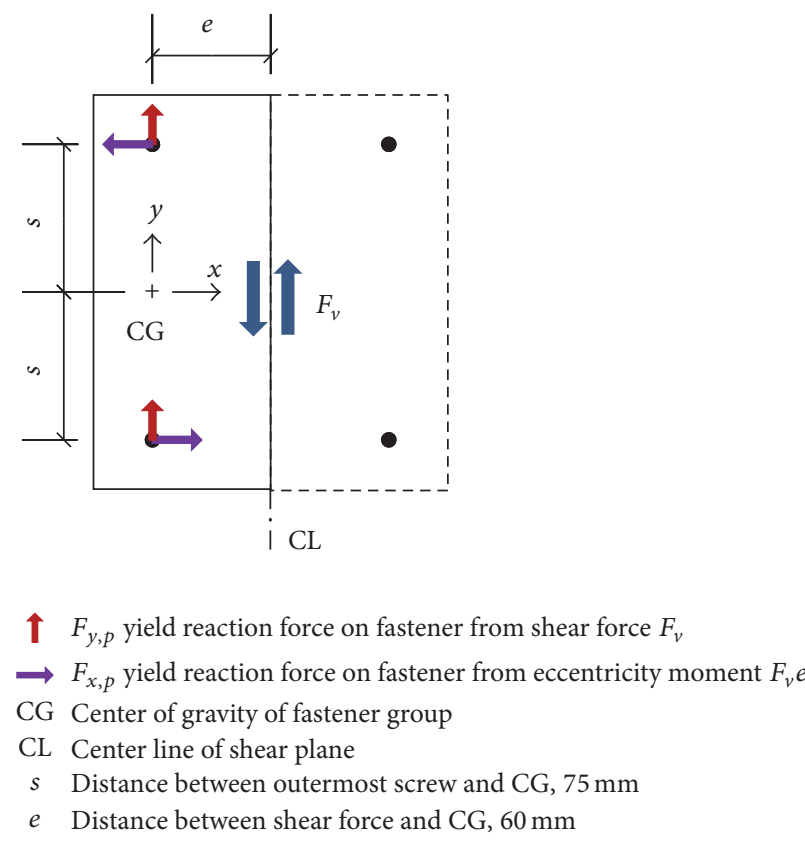

(a)

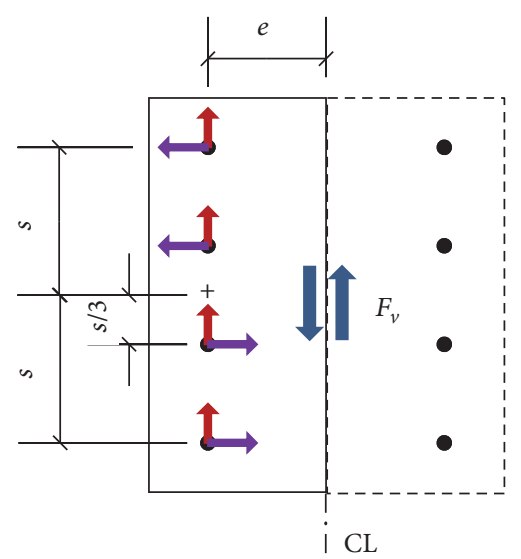

$1 F_{y, p}$ yield reaction force on fastener from shear force $F_{v}$

$\rightarrow F_{x, p}$ yield reaction force on fastener from eccentricity moment $F_{v} e$

CG Center of gravity of fastener group

CL Center line of shear plane

$s$ Distance between outermost screw and CG, $75 \mathrm{~mm}$

$e$ Distance between shear force and CG, $60 \mathrm{~mm}$

(b)

Figure 16: Connection plate subjected to shear force according to Figure 3(b): (a) fastener forces for a double screw configuration and (b) fastener forces for a four-screw configuration.

configuration. For the two-screw connection (Figure 16(a)), this gives

$$
\begin{aligned}
& F_{y, p}=\frac{F_{v}}{2}=F_{v_{1}(2)}, \\
& F_{x, p}=\frac{F_{v} e}{2 s},
\end{aligned}
$$

where $F_{v_{1}(2)}$ denotes the load on each of the fasteners from pure shear force only in case of a two-screw connection. The resultant fastener force, due to the eccentricity in a double screw connection according to a plastic model, becomes

$$
\begin{aligned}
F_{\mathrm{ecc}(2), p} & =\sqrt{F_{y, p}^{2}+F_{x, p}^{2}}=\frac{1}{2} F_{v} \sqrt{1+\left(\frac{e}{s}\right)^{2}} \\
& =F_{v_{1}(2)} \sqrt{1+\left(\frac{e}{s}\right)^{2}} .
\end{aligned}
$$

Similarly, the four-screw configuration (Figure 16(b)) gives

$$
\begin{aligned}
F_{y, p} & =\frac{F_{v}}{4}=F_{v_{1}(4)}, \\
F_{x, p} & =\frac{3}{8} \frac{F_{v} e}{s}, \\
F_{\mathrm{ecc}(4), p} & =\frac{1}{4} F_{v} \sqrt{1+\frac{9}{4}\left(\frac{e}{s}\right)^{2}}=F_{v_{1}(4)} \sqrt{1+\frac{9}{4}\left(\frac{e}{s}\right)^{2}},
\end{aligned}
$$

where $F_{v_{1}(4)}$ is the load on each of the fasteners from pure shear load only in case of a four-screw connection. For comparison, a corresponding analysis based on elasticity would give $F_{\mathrm{ecc}(4), e}=F_{v_{1}(4)} \sqrt{1+(9 e / 5 s)^{2}}$.

In the shear tests according to Figure $3(\mathrm{~b})$, the grain direction of the LVL core is perpendicular to the shear plane. Hence, the resultant of the two components in the $x$ - and $y$ direction forms the following angle with this grain direction,

$$
\begin{aligned}
& \beta_{2}=\arctan \left(\frac{F_{y, p}}{F_{x, p}}\right)=\arctan \left(\frac{s}{e}\right), \\
& \beta_{4}=\arctan \left(\frac{F_{y, p}}{F_{x, p}}\right)=\arctan \left(\frac{2 s}{3 e}\right) .
\end{aligned}
$$

The embedment strength in an arbitrary direction can be expressed as

$$
f_{h, w, \beta}=\frac{f_{h, w, 90}}{\left(f_{h, w, 90} / f_{h, w, 0}\right) \cos ^{2} \beta+\sin ^{2} \beta} .
$$

The parameter $\gamma$ as introduced in (2) is then given by $\gamma_{\beta}=$ $f_{h, b} / f_{h, w, \beta}$. Note that a change in this parameter changes the capacity of the failure modes discussed in Section 5.1, both directly and indirectly; that is, it changes indirectly the position of $x_{w}$ or $x_{b}$.

6.2. Experimental and Analytical Comparison. The geometrical values shown in Figures 4,14 , and 16 are $t_{b}=8 \mathrm{~mm}$, $t_{w}=26 \mathrm{~mm}, t_{s}=4 \mathrm{~mm}, t_{p}=3 \mathrm{~mm}, e=60 \mathrm{~mm}, s=75 \mathrm{~mm}$, 
TABLE 5: Experimental and analytical shear capacities for the fastener in the uplift tests (loading parallel to grain).

\begin{tabular}{|c|c|c|c|c|c|c|c|c|c|}
\hline \multirow[b]{2}{*}{$\begin{array}{l}\text { Number of } \\
\text { Screws }\end{array}$} & \multicolumn{9}{|c|}{ Shear capacity per fastener $[\mathrm{kN}]$} \\
\hline & $\begin{array}{l}\text { Uplift test } \\
\text { (Table 1) }\end{array}$ & $\begin{array}{c}\text { Mode } a \\
R_{a} \\
(3)\end{array}$ & $\begin{array}{c}\text { Mode } b \\
R_{b} \\
(4)\end{array}$ & $\begin{array}{c}\text { Mode } c 1 \\
R_{c 1} \\
(7)\end{array}$ & $\begin{array}{c}\text { Mode } c 2 \\
R_{c 2} \\
(10)\end{array}$ & $\begin{array}{c}\text { Mode } c 3 \\
R_{c 3} \\
(33)\end{array}$ & $\begin{array}{c}\text { Mode } d \\
R_{d} \\
(13)\end{array}$ & $\begin{array}{c}\text { Mode } e \\
R_{e} \\
(16)\end{array}$ & $\begin{array}{c}\text { Mode } f \\
R_{f} \\
(22)\end{array}$ \\
\hline \multicolumn{10}{|c|}{ Parallel to grain } \\
\hline 1 & 7.42 & 12.84 & 12.87 & $*$ & 6.76 & 6.33 & * & 8.85 & 6.76 \\
\hline 2 & 6.84 & - & - & - & - & - & - & - & - \\
\hline 4 & 6.28 & - & - & - & - & - & - & - & - \\
\hline \multicolumn{10}{|c|}{$\begin{array}{l}\text { Perpendicular } \\
\text { to grain }\end{array}$} \\
\hline 1 & 5.09 & 10.42 & 12.87 & $*$ & 5.37 & $*$ & $*$ & 7.51 & 5.41 \\
\hline
\end{tabular}

$d_{\text {nom }}=6.7 \mathrm{~mm}, d_{\text {eff }}=5.8$. The density of the LVL is $\rho_{w \text {,mean }}=$ $424 \mathrm{~kg} / \mathrm{m}^{3}$. According to Sections 4.4 and 4.5 , the yield moment is $M_{p \text {, mean }}=21.2 \mathrm{Nm}$, and the embedment strengths are $f_{h, b, \text { mean }}=71.0 \mathrm{~N} / \mathrm{mm}^{2}, f_{h, w, 0, \text { mean }}=49.0 \mathrm{~N} / \mathrm{mm}^{2}$, and $f_{h, w, 90 \text {, mean }}=30.0 \mathrm{MPa}$; that is,

$$
\begin{gathered}
\gamma_{\beta=0}=\frac{f_{h, b}}{f_{h, w, 0}}=\frac{71.0}{49.0}=1.45, \\
\gamma_{\beta=90}=\frac{f_{h, b}}{f_{h, w, 90}}=\frac{71.0}{30.0}=2.37 .
\end{gathered}
$$

6.2.1. The Uplift Tests. The yield capacities for the different failure modes in the uplift tests are given in Table 5.

It is evident from Table 5 that the coefficient for effective number of screws is $\eta_{\text {eff, } 2}=0.92$ in a double screw connection and $\eta_{\text {eff } 4}=0.85$ in a four-screw connection and that the experimental value $(7.42 \mathrm{kN})$ and the analytical value of the failure modes $c 2(6.76 \mathrm{kN})$ and $f(6.76 \mathrm{kN})$ differ by $8.9 \%$. Considering the rope effect and the clamping effect from the screw head, the agreement is very good. However, it is observed that the failure mode at maximum load according to Figure 6(a) is somewhat different from that one assumed in the analytical model. In the real connection only the point of the fastener penetrated the rear board layer. In addition, the predrilling was made only up to half of the second board layer and, which is evident from the figure, the screw pushed out the board material and partly damaged the embedment of the board layer. Hence, a reduced part of the theoretical embedment support of the board layer is acting in the deformation process. Therefore, an additional failure mode is considered for comparison as discussed below.

Concerning the tests perpendicular to grain, it is noted that the experimental result $(5.09 \mathrm{kN})$ is lower than the lowest theoretical failure load $(5.37 \mathrm{kN})$. The main reason for the reduction of failure load is probably due to preexisting drying cracks in the LVL core, which both could be observed visually prior to testing and also heard as crack sounds during the tests. It is generally noted that, in PlyBoard panels, the hardboard layers constrain the moisture movement in the
LVL, which can be considerable in the perpendicular to grain direction, and, hence, increasing the tendency for crack formation. These cracks can occur a certain time after the manufacturing of the PlyBoard panels due to drying. In this case, the test specimens were exposed to a drying period of approximately two years.

6.2.2. Failure Mode (c3) for Short Nail: Embedment Failure in the LVL Core and in One Hardboard Layer Combined with a Plastic Hinge in the Fastener; Sign Shift of the Shear Force within the Board Layer. Thus, it is expedient to assume an adjusted failure mode based on the observation of the test results (cf. Figure 6(a)). The fastener in the experiments has a length equal to the thickness of the PlyBoard, but it is a self-drilling screw with a tapering point of a length about the thickness of the hardboard layer. Since the PlyBoard was predrilled only up to half of the hardboard layer at the far end, the board material was pushed out and partly damaged the support from the board (cf. Figure 6(a)). Hence, the embedment of the screw was essentially only effective in the LVL core. This model corresponds to the situation where the rear board is destroyed during the mounting of the screw when the hardboard is not predrilled.

A failure mode with a plastic hinge, as illustrated in Figure 14(c3), is possible depending on the geometry and the material properties of the connection. If the conditions are such that the embedment stresses to the left of the slotted-in plate in Figure 14(c3) basically occur only in the LVL core and do not extend into the rear board layer, that is, the moment equilibrium to the left of the plastic hinge is fulfilled for $\xi \geq 0$, and the sign shift of the shear force is taking place in the front hardboard layer, then the load-carrying capacity can be derived as shown below. If $\xi$ is close to zero in this specific case, this failure mode may be realistic.

From vertical equilibrium we have

$$
\begin{aligned}
& R_{c 3}=f_{h, w} t_{w} d\left[1-\frac{t_{s}+\xi}{t_{w}}+\gamma \frac{2 x_{b}-t_{b}}{t_{w}}\right], \\
& 0 \leq \xi \leq \frac{1}{2}\left(t_{w}-t_{s}\right), 0 \leq x_{b} \leq t_{b} .
\end{aligned}
$$


The distance $\xi$ is obtained from moment equilibrium of the left part in Figure 14(c3); that is,

$$
M_{p}=\frac{1}{8} f_{h, w} d\left[4 \xi^{2}-4 t_{w} \xi+\left(t_{w}^{2}-t_{s}^{2}\right)\right]
$$

and, therefore,

$$
\xi=\frac{1}{2} t_{w}\left[1-\sqrt{1+\frac{8 M_{p}}{f_{h, w} t_{w}^{2} d}-\left(1-\frac{t_{s}^{2}}{t_{w}^{2}}\right)}\right] .
$$

The distance $x_{b}$ is obtained from moment equilibrium of the right part in Figure 14(c3); that is,

$$
\begin{aligned}
M_{p}= & \frac{1}{8} f_{h, w} d\left(t_{w}^{2}-t_{s}^{2}\right) \\
& +f_{h, b} d\left[x_{b}^{2}+t_{w} x_{b}-\frac{1}{2} t_{b}\left(t_{b}+t_{w}\right)\right]
\end{aligned}
$$

and, hence,

$$
\begin{aligned}
x_{b} & =\frac{1}{2} t_{w}[-1 \\
& \left.+\sqrt{1+\frac{4 M_{p}}{f_{h, b} t_{w}^{2} d}-\frac{1}{2 \gamma}\left(1-\frac{t_{s}^{2}}{t_{w}^{2}}\right)+2 \frac{t_{b}}{t_{w}}\left(1+\frac{t_{b}}{t_{w}}\right)}\right] .
\end{aligned}
$$

In the experimental case with $d_{\text {eff }}=5.8 \mathrm{~mm}, M_{p}=21.2 \mathrm{Nm}$, $f_{h, w, 0}=49.0 \mathrm{MPa}$, and $f_{h, b, 0}=71.0 \mathrm{MPa}$, we obtain $\xi=$ $0.623 \mathrm{~mm}, x_{b}=4.31 \mathrm{~mm}$, and $R_{c 3}=6.33 \mathrm{kN}$. For comparison with respect to failure mode $(f)$, where both hardboard layers act as rigid supports, the load-carrying capacity is $R_{f}=$ $6.76 \mathrm{kN}$. Obviously, failure mode $(c 3)$ gives lower capacity value than failure mode $(f)$, about $7 \%$. It is noted that failure mode $(f)$ gives practically the same capacity as failure mode (c2).

6.2.3. The Shear Tests. The eccentricity introduced by the shear load increases the load effect on the fasteners as shown in (26) and (29), where the load on the individual fastener corresponds to $R_{i}$, the capacity of the governing failure mode $i$ as given in Section 5.1. According to (30), the angles between the force and grain directions become $\beta_{2}=51.3^{\circ}$ and $\beta_{4}=39.8^{\circ}$, respectively, and according to (31), the embedment strengths become $f_{h, w, 53.1^{\circ}}=34.9 \mathrm{MPa}$ and $f_{h, w, 39.8^{\circ}}=38.9 \mathrm{MPa}$, respectively. Hence the relative embedment strength becomes $\gamma_{2}=2.03$ and $\gamma_{4}=1.83$, respectively. According to (10), the load-carrying capacity for failure mode $c 2$ then becomes $R_{c 2,2 \text { screws }}=5.73 \mathrm{kN}$ and $R_{c 2,4 \text { screws }}=6.03 \mathrm{kN}$ for the double and the four-screw connections, respectively. Accounting for the eccentricity according to (26) and (29), the analytical capacities are given by

$$
\begin{aligned}
& F_{v_{1}(2)} \leq \frac{5.73}{\sqrt{1+(60 / 75)^{2}}}=4.47 \mathrm{kN}, \\
& F_{v_{1}(4)} \leq \frac{6.03}{\sqrt{1+(9 / 4)(60 / 75)^{2}}}=3.86 \mathrm{kN} .
\end{aligned}
$$

These values should be compared with the ultimate shear load per fastener from the tests according to Table 2 , that is, $4.88 \mathrm{kN}(9.75 / 2)$ for the two-screw configuration (8.4\% difference) and $4.24 \mathrm{kN}(16.97 / 4)$ for the four-screw configuration (9.0\% difference). As is proper, the analytical formulas give conservative values for the load-carrying capacity.

\section{Conclusions}

The slotted-in steel-plate connection in PlyBoard elements is studied experimentally and analytically. The application is as splicing and anchoring devices in stabilizing shear walls experiencing vertical uplift forces and horizontal shear forces. Load-slip curves are determined both with respect to vertical uplift forces and to horizontal shear forces for different designs of the connection. In case of vertical uplift, the curves are characterized by a fairly steep ascending part to the maximum load and then a gradually decreasing descending part. In case of shear forces, the curves show a high degree of plastic behaviour. Thus, the curves can be considered sufficiently ductile in order to allow plastic design methods for the connection to be used. Analytical expressions for the loadcarrying capacity of single connections are derived using the Johansen yield model. For multiple screw connections in shear, the effect of eccentricity and orthotropic material behaviour are taken into account. Good agreement between analytical and experimental results is obtained.

\section{Competing Interests}

The authors declare that there is no conflict of interests regarding the publication of this paper.

\section{Acknowledgments}

The authors wish to express their sincere appreciation to Tekn.Lic. Per-Anders Daerga for conducting the tests and his valuable and comprehensive contribution concerning their evaluation and producing figures and manuscript proposal (in spite of his contribution, he has asked not to be involved in the ensuing final authoring work). This work was supported by the County Administrative Board in Norrbotten; the Regional Council of Västerbotten; and the European Union: European Regional Development Fund-Regional Structural Fund, Interregional Programmes, and the Swedish Governmental Agency for Innovation Systems, Vinnova.

\section{References}

[1] J. Kolb, "Multi-storey timber buildings," in Systems in Timber Engineering, pp. 182-200, Birkhäuser, Berlin, Germany, 2008.

[2] Masonite Beams AB, MFB Handbook, 2010 (Swedish).

[3] P. A. Daerga, U. A. Girhammar, and B. Källsner, "The masonite flexible building system for multi-storey timber buildings," in Proceedings of the 12th World Conference on Timber Engineering (WCTE '12), Auckland, New Zealand, 2012. 
[4] P. A. Daerga, U. A. Girhammar, and B. Källsner, "Suspended floor element connections for the Masonite flexible building system," in Proceedings of the 12th World Conference on Timber Engineering (WCTE '12), Auckland, New Zealand, 2012.

[5] B. Madsen and K. C. Johns, "Behaviour of timber connections," Canadian Journal of Civil Engineering, vol. 28, no. 3, article 546, 2001.

[6] T. Dyken and O. Kleppe, "The norwegian approach to modern timber bridge design," in Proceedings of the 25th International Baltic Road Conference, Vilnius, Lithuania, 2003.

[7] R. B. Abrahamsen, "Bridge across Rena River- "World's strongest timber bridge", in Proceedings of the 10th World Conference on Timber Engineering, pp. 302-309, Miyazaki, Japan, June 2008.

[8] B. Källsner and U. A. Girhammar, "Plastic models for analysis of fully anchored light-frame timber shear walls," Engineering Structures, vol. 31, no. 9, pp. 2171-2181, 2009.

[9] B. Källsner and U. A. Girhammar, "Plastic design of partially anchored wood-framed wall diaphragms with and without openings," in Proceedings of the CIB-W18 Meeting, Karlsruhe, Germany, 2005.

[10] B. Källsner and U. A. Girhammar, "Horizontal stabilising of light frame timber structures-plastic design of wood-framed shear walls," SP Report 2008:47, SP Technical Research Institute of Sweden, Stockholm, Sweden, 2009.

[11] B. Källsner, U. A. Girhammar, and J. Vessby, "Evaluation of two analytical plastic design models for light-frame shear walls," in Proceedings of the World Conference on Timber Engineering 2012 (WCTE '12), Auckland, New Zealand, July 2012.

[12] U. A. Girhammar and B. Källsner, "Horizontal stabilisation of sheathed timber frame structures using plastic design methods-introducing a handbook Part 1: design principles for horizontal stabilisation," Procedia Engineering, vol. 161, pp. 618627, 2016.

[13] U. A. Girhammar and B. Källsner, "Horizontal stabilisation of sheathed timber frame structures using plastic design methods-introducing a handbook Part 2: design of joints and anchoring devices," Procedia Engineering, vol. 161, pp. 628-635, 2016.

[14] B. Källsner and U. A. Girhammar, "Horizontal stabilisation of sheathed timber frame structures using plastic design methods-introducing a handbook Part 3: basics of the plastic design method," Procedia Engineering, vol. 161, pp. 636-644, 2016.

[15] B. Källsner and U. A. Girhammar, "Horizontal stabilisation of sheathed timber frame structures using plastic design methods-introducing a handbook Part 4: design in ultimate limit state," Procedia Engineering, vol. 161, pp. 645-654, 2016.

[16] Qualisys AB, http://www.qualisys.se.

[17] P. A. Daerga, "Programming of Matlab-routines for evluation of experiments on connections in the MFB-system," Technical Report, Luleå University of Technology, Luleå, Sweden, (originally presented as an internal report, Umeå University, 2014), 2017 (Swedish).

[18] Kartro AB, http://www.kartro.se.

[19] "EN 1995-1-1:2004(E)-Eurocode 5-Design of timber structuresPart 1-1: General-Common rules and rules for buildings, European Committee for Standardisation (CEN)," 2009.

[20] U. A. Girhammar, N. I. Bovim, and B. Källsner, "Characteristics of sheathing-to-timber joints in wood shear walls," in Proceedings of the 8th World Conference on Timber Engineering (WCTE '04), Lahti, Finland, 2004.
[21] M. Rios, Improved design of the element-to-element connector of the MFB-system [M.S. thesis 293], Royal Institute of Technology, Stockholm, Sweden, 2010 (Swedish).

[22] K. W. Johansen, "Theory of timber connectors," in Proceedings of the International Association of Bridge and Structural Engineering (IABSE '49), vol. 9, pp. 249-262, 1949. 


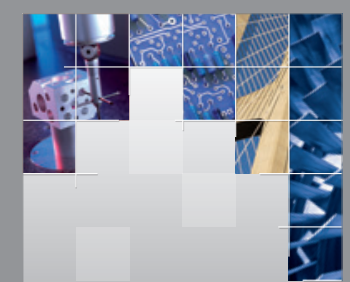

\section{Enfincering}
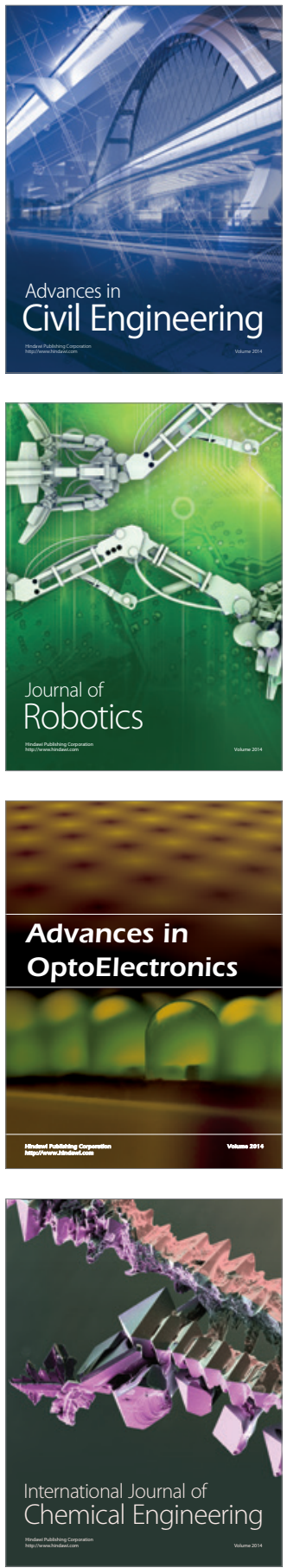

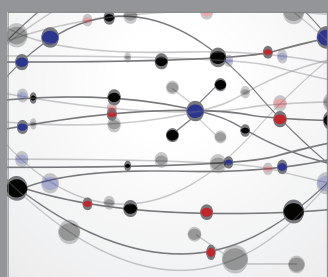

The Scientific World Journal

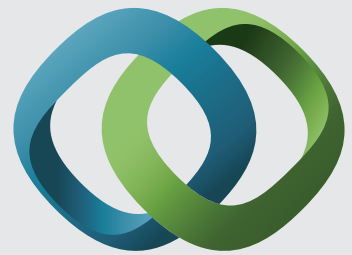

\section{Hindawi}

Submit your manuscripts at

https://www.hindawi.com
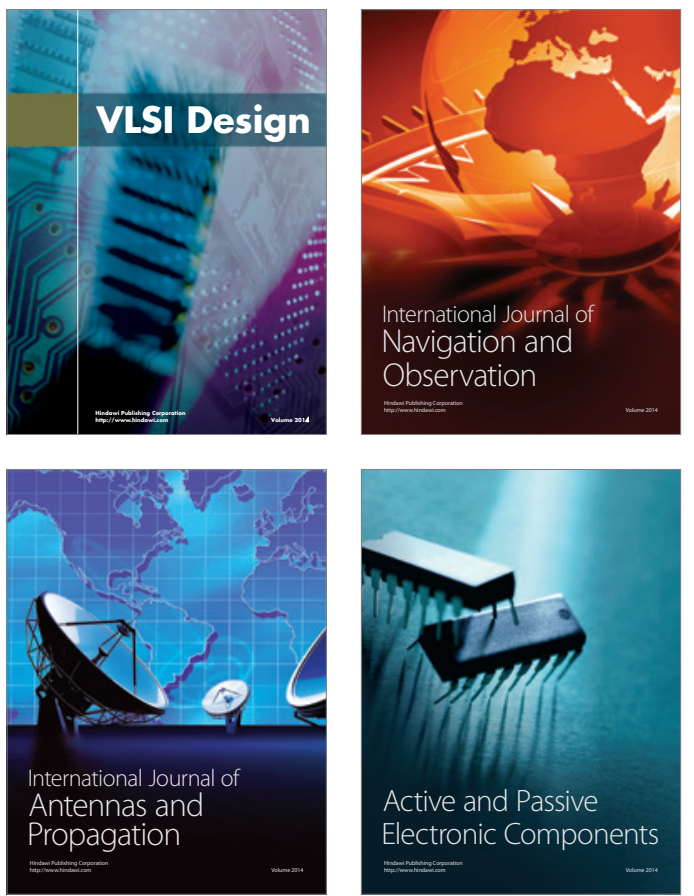
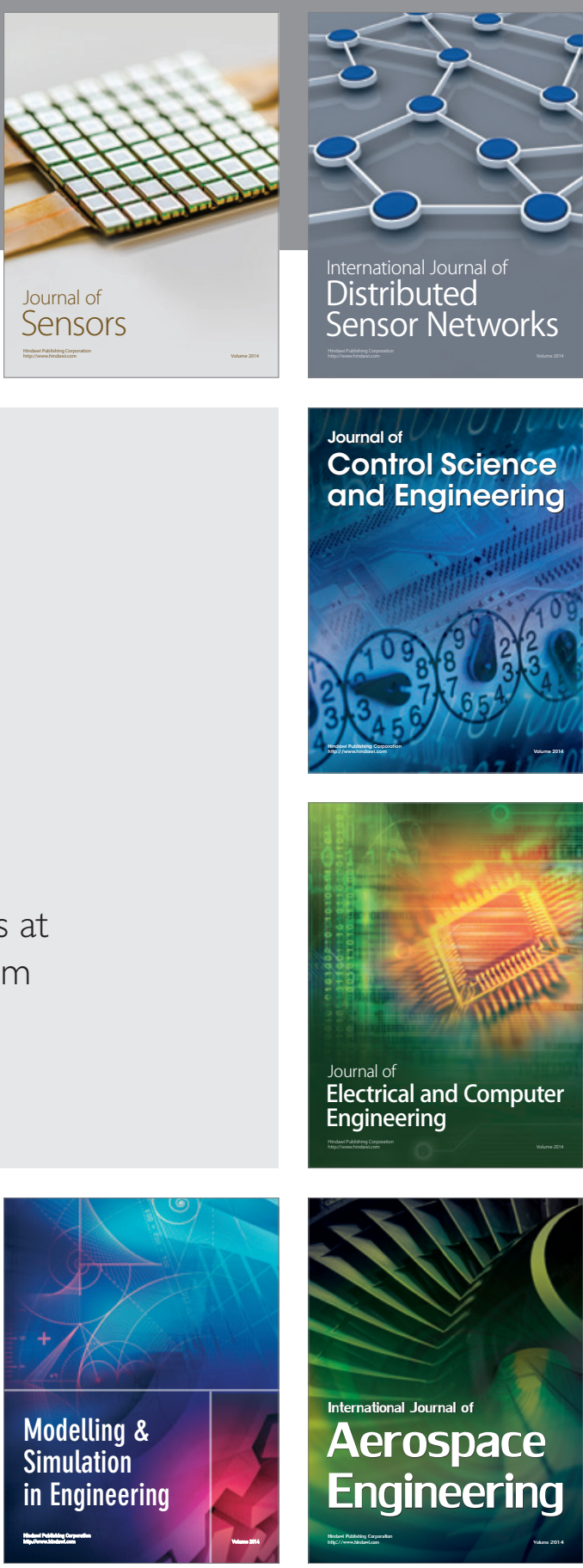

International Journal of

Distributed

Sensor Networks

$-$

Joumal of

Control Science

and Engineering
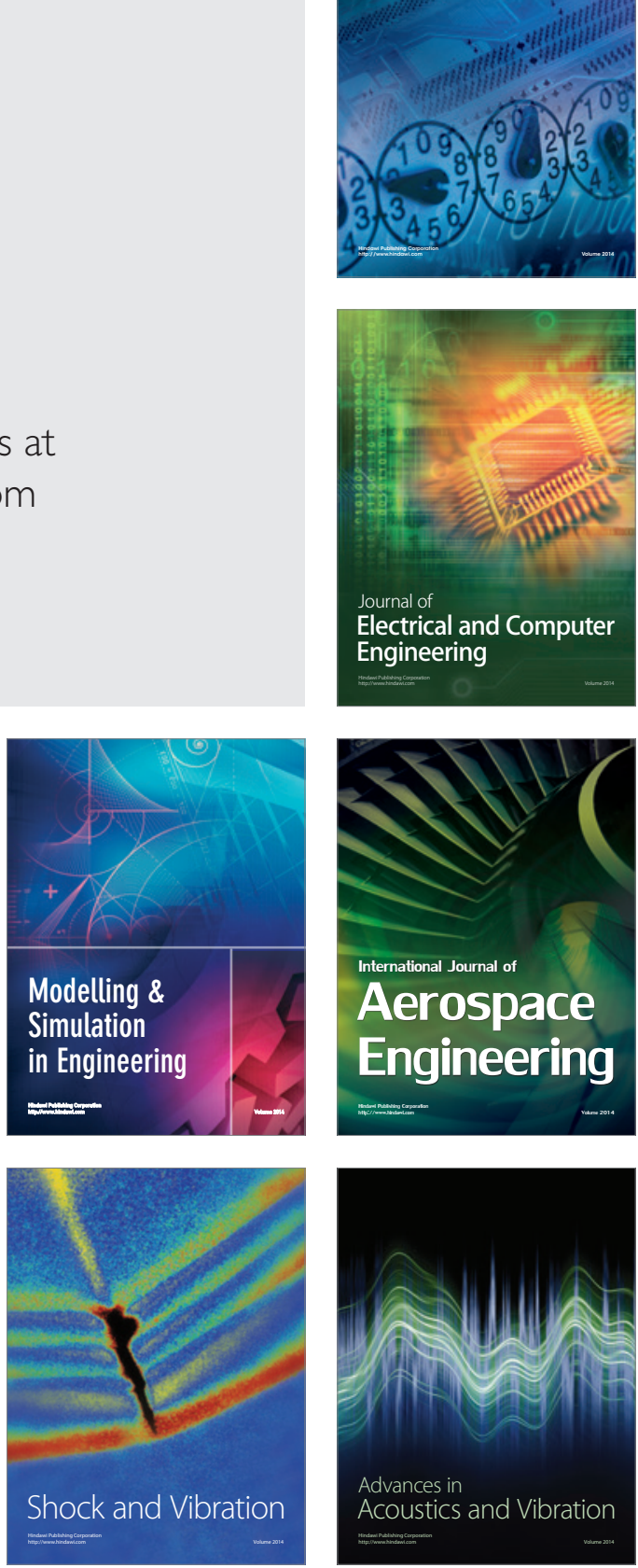